\title{
Cholinergic innervation of principal neurons in the cochlear nucleus of the Mongolian gerbil
}

\author{
Charlène Gillet $^{1 *}$ | David Goyer2* (b) | Stefanie Kurth ${ }^{1}$ | Hannah Griebel ${ }^{1}$ | \\ Thomas Kuenzel ${ }^{1}$
}

${ }^{1}$ Institute for Biology 2, RWTH Aachen University, Aachen, D-52074, Germany

${ }^{2}$ Department of Otolaryngology - Head and Neck Surgery, University of Michigan, Kresge Hearing Research Institute, Ann Arbor, Michigan, 48109

\section{Correspondence}

Thomas Kuenzel, Institute for Biology 2, RWTH Aachen University, Worringer Weg 3, Aachen, D-52074, Germany.

Email: kuenzel@bio2.rwth-aachen.de

Funding information

Deutsche Forschungsgemeinschaft, Grant/ Award Number: KU2529/2-2

\begin{abstract}
Principal neurons in the ventral cochlear nucleus (VCN) receive powerful ascending excitation and pass on the auditory information with exquisite temporal fidelity. Despite being dominated by ascending inputs, the VCN also receives descending cholinergic connections from olivocochlear neurons and from higher regions in the pontomesencephalic tegmentum. In Mongolian gerbils, acetylcholine acts as an excitatory and modulatory neurotransmitter on VCN neurons, but the anatomical structure of cholinergic innervation of gerbil VCN is not well described. We applied fluorescent immunohistochemical staining to elucidate the development and the cellular localization of presynaptic and postsynaptic components of the cholinergic system in the VCN of the Mongolian gerbil. We found that cholinergic fibers (stained with antibodies against the vesicular acetylcholine transporter) were present before hearing onset at P5, but innervation density increased in animals after P10. Early in development cholinergic fibers invaded the VCN from the medial side, spread along the perimeter and finally innervated all parts of the nucleus only after the onset of hearing. Cholinergic fibers ran in a rostro-caudal direction within the nucleus and formed en-passant swellings in the neuropil between principal neurons. Nicotinic and muscarinic receptors were expressed differentially in the VCN, with nicotinic receptors being mostly expressed in dendritic areas while muscarinic receptors were located predominantly in somatic membranes. These anatomical data support physiological indications that cholinergic innervation plays a role in modulating information processing in the cochlear nucleus.
\end{abstract}

\section{KEYWORDS}

acetylcholine, cochlear nucleus, olivocochlear system, endbulb of held, spherical bushy cells, RRID: AB_887864, RRID:AB_2079760, RRID:AB_90764, RRID:AB_2080193, RRID:AB_2039997, RRID: AB_2315385

\section{1 | INTRODUCTION}

The principal neurons of the cochlear nucleus $(\mathrm{CN})$ receive direct excitatory inputs (Cao \& Oertel, 2010) from the auditory nerve (AN). CN outputs project bilaterally into higher stations of the auditory pathway, including the superior olivary complex (Cant \& Casseday, 1986) and the inferior colliculus (Adams, 1979; Nordeen, Killackey, \& Kitzes, 1983). The circuitry involved in sound localization with binaural parameters, which originates in the bushy cells (BC) of the VCN, is well

${ }^{*}$ Charlene Gillet and David Goyer contributed equally. studied (reviewed for example in Grothe, Pecka, \& McAlpine, 2010; Grothe \& Pecka, 2014). Bushy cells receive powerful excitatory inputs via axosomatic AN terminals, called endbulbs of Held (Held, 1893; for reviews see: Ryugo \& Parks, 2003; Felmy \& Künzel, 2014). A number of inhibitory and secondary influences on $B C$ that interact with the excitation have been identified (Oertel, 1983; Wickesberg \& Oertel, 1988; Gómez-Nieto \& Rubio, 2009; Campagnola \& Manis, 2014). Inhibition, for example, dynamically influences how the dominant excitatory inputs are processed by these neurons (Kopp-Scheinpflug, Dehmel, Dörrscheidt, \& Rübsamen, 2002; Kuenzel, Borst, \& van der Heijden, 2011; Kuenzel, Nerlich, Wagner, Rübsamen, \& Milenkovic, 
2015; Nerlich et al., 2014; Keine \& Rübsamen, 2015; Keine, Rübsamen, \& Englitz, 2016). Furthermore, the CN is also targeted by descending modulatory inputs using acetylcholine as neurotransmitter (Comis \& Davies, 1969; Sherriff \& Henderson, 1994; Happe \& Morley, 1998; Behrens, Schofield, \& Thompson, 2002; Mellott, Motts, \& Schofield, 2011). The functional relevance of the cholinergic inputs to the early central stages of the auditory pathway is poorly understood. Cholinergic inputs affect neurons in the dorsal CN (DCN) (Caspary, Havey, \& Faingold, 1983; Irie, Fukui, \& Ohmori, 2006; Manzoor, Chen, \& Kaltenbach, 2013; He, Wang, Petralia, \& Brenowitz, 2014; Stefanescu \& Shore, 2016) and VCN (Caspary et al., 1983; Fujino \& Oertel, 2001; Goyer et al., 2016) via nicotinic and muscarinic acetylcholine receptors. However, even for the well-studied stellate and bushy neurons in the anteroventral cochlear nucleus (AVCN) the role of the cholinergic modulation in hearing has only been vaguely defined (Künzel \& Wagner, 2017). This is complicated by the fact that cholinergic axons projecting into the $\mathrm{CN}$ arise from more than one source: a large portion of cholinergic inputs to the $\mathrm{CN}$ are formed by collaterals of the descending olivocochlear bundle (OCB; Ryan, Keithley, Wang, \& Schwartz, 1990; Horváth, Kraus, \& Illing, 2000; Mulders, Winter, \& Robertson, 2002; Guinan, 2006; Kishan, Lee, \& Winer, 2011; Baashar, Robertson, \& Mulders, 2015). Other sources of cholinergic axons are found in the pontomesencephalic tegmentum (Schofield, Motts, \& Mellott, 2011; Mellott et al., 2011), which widely project into the lower auditory pathway. Whether these cholinergic connections contact the same neuronal targets and/or are distinguishable from the OCB axons is unclear however.

In this study, we aimed to better describe the cellular localization, development, and postsynaptic structure of the cholinergic innervation of the $\mathrm{CN}$ of the Mongolian gerbil. The Mongolian gerbil is an established animal model for studying the neurobiology of sound localization at lower frequencies. Therefore, special focus was lain on the AVCN and the endbulb of Held to bushy cell connectivity, as this is a critical station in the pathway for sound source localization. We showed with fluorescent immunohistochemical staining that cholinergic inputs target the bushy dendrite of BC and were very prominently present after hearing onset in all parts of the VCN, supporting the notion of a functional role of cholinergic modulation in the mature sense of hearing.

\section{I MATERIALS AND METHODS}

All experiments were conducted in the laboratories of the Institute for Biology 2 at RWTH Aachen University, Germany and were in accordance with the European Communities Council Directive of 24 November 1986 (86/609/EEC) and approved by local state authorities (North Rhine-Westphalia State Agency for Nature, Environment and Consumer Protection, Recklinghausen, Germany).

\subsection{SDS-PAGE and Western blot}

Brains from Mongolian gerbils (Meriones unguiculatus) of postnatal day (P)14 to P31 were used to characterize the primary antibodies used for this study (summarized in Table 1). Gerbils were deeply anesthetized with isoflurane and decapitated. The brain was quickly removed and brainstem chunks were processed for sodium dodecyl sulfate polyacrylamide gel electrophoresis (SDS-PAGE) as previously described for chicken in Goyer, Fensky, Hilverling, Kurth, and Kuenzel (2015). In brief, brainstem chunks were triturated with $2.5 \mu \mathrm{L}$ hypotonic lysis buffer (30 mM NaCl, 2\% Triton X-100, 10 mM phosphate buffer (PB), $\mathrm{pH} 7.4,10 \mu \mathrm{L} / \mathrm{mL}$ Sigma Protease Inhibitor cocktail) per milligram of tissue. Homogenates were centrifuged at $4^{\circ} \mathrm{C}, 12,400 \mathrm{~g}$ for $15 \mathrm{~min}$ Supernatants were stored at $-80^{\circ} \mathrm{C}$ for further processing. Protein concentrations of all homogenates were determined with the bicinchoninic acid assay (Sigma, St Louis, MO). After boiling the samples for one minute, gel lanes were loaded with $20 \mu \mathrm{g}$ protein in loading buffer ( $62.5 \mathrm{mM}$ Tris, 2\% SDS, 10\% sucrose and a piece of bromphenol blue). Discontinuous SDS-PAGE was performed to separate proteins. First, proteins were run into a $3.5 \%$ collection gel ( $15 \mathrm{~min}, 15 \mathrm{~mA}$ current) and then into a $7.5 \%$ separation gel ( $1 \mathrm{hr}, 30 \mathrm{~mA}$ current). Then, proteins were transferred onto nitrocellulose membranes (MiniProtean System; Bio-Rad, Hercules, CA) by standard Western blot (WB) procedures (Mini Gel Holder Cassette, BioRad; 200-400 mA current for $1 \mathrm{hr}$ on ice). After blocking (5\% milk powder with $0.1 \%$ Tween-20 in Trisbuffered saline) overnight at $4^{\circ} \mathrm{C}$, blot membranes were exposed to the primary antibodies for $2 \mathrm{hr}$ at room temperature. Bound primary antibodies were detected using peroxidase-conjugated secondary antibodies (1:5,000; goat anti-rabbit, Sigma and donkey anti-rabbit, Abcam) and an enhanced chemiluminescence reaction (GE Healthcare, Piscataway, NJ) in accordance to the manufacturer's instructions. X-ray films were exposed to chemiluminescent light for $30 \mathrm{~s}$ to $1 \mathrm{~min}$. Exposed $\mathrm{X}$ ray films were developed with standard methods and digitized.

\section{2 | Fluorescence immunohistochemistry}

Gerbils of either sex aged P5 to P31 were used for immunohistochemistry as previously described in Goyer et al. (2016). Briefly, gerbils of P18 or older were terminally anesthetized with an overdose of $>150 \mathrm{mg} / \mathrm{kg}$ body weight Ketamine (Ceva Tiergesundheit $\mathrm{GmbH}$, Düsseldorf, Germany) and then transcardially perfused with ice-cold PB and $4 \%$ paraformaldehyde (PFA) in PB. For gerbils younger than P17 transcardial perfusion was not performed but were simply deeply anesthetized with isoflurane and decapitated. The brains were removed and fixed by immersion in 4\% PFA in PB overnight. After fixation, the brains were successively transferred into $10 \%$ and $30 \%$ sucrose solution for cryoprotection. Brains were embedded in Tissue-Tek (Sakura Finetek, AJ Alphen aan den Rijn, The Netherlands) and $30 \mu \mathrm{m}$ sections were cut either in the frontal or parasagittal plane on a cryotome (CM3050S, Leica Biosystems, Wetzlar, Germany) and collected on coated slides (Scientific Menzel-Gläser Superfrost Plus). Double immunohistochemical staining was performed in the following steps. The sections were first rinsed with phosphate buffered saline (PBS) and incubated for $3 \mathrm{hr}$ at room temperature with blocking solution (4\% normal horse serum (NHS), 0.4\% Triton X-100, 1\% bovine serum-albumine (BSA) in PBS). Secondly, the sections were incubated with primary antibody solution (1\% NHS, 0.3\% Triton X-100, 1\% BSA in PBS) for $24 \mathrm{hr}$ at $4{ }^{\circ} \mathrm{C}$. Next, sections were washed in PBS and incubated with 
TABLE 1 All primary and secondary antibodies used for immunohistofluorescence as well as their concentration and reference information

$\begin{array}{lllll}\text { Target protein } & \text { Species } & \text { Final Concentration } & \text { Source, Cat. No } & \text { RRID } \\ \text { Primary antibodies } & & & & \text { AB_887864 } \\ \text { VAChT } & \text { rabbit } & 3 \mu \mathrm{g} / \mathrm{mL} & \text { Synaptic System, 139 103 } & \text { AB_90764 } \\ \text { Calretinin } & \text { goat } & 1: 500^{\mathrm{a}} & \text { Millipore, AB1550 } & \text { AB_2079760 } \\ \text { ChAT } & \text { rabbit } & 5 \mu \mathrm{g} / \mathrm{mL} & \text { Millipore, AB143 } & \text { AB_2080193 } \\ \text { M3 muscarinic receptor (1) } & \text { rabbit } & 10 \mu \mathrm{g} / \mathrm{mL} & \text { MBL International, LS-5259 } & \text { AB_2039997 } \\ \text { M3 muscarinic receptor (2) } & \text { rabbit } & 16 \mu \mathrm{g} / \mathrm{mL} & \text { Alomone labs, AMR-006 } & \text { RRID } \\ \text { Antibody } & \text { Fluorophore } & \text { Final Concentration } & \text { Source, Cat. No } & \\ \text { Secondary antibodies } & & & \text { Thermo Fischer Scientific, A-21206 } \\ \text { Donkey anti-rabbit } & 488 & 4 \mu \mathrm{g} / \mathrm{mL} & \text { Thermo Fischer Scientific, A-10040 } & \text { AB_2535792 } \\ \text { Donkey anti-rabbit } & 546 & 4 \mu \mathrm{g} / \mathrm{mL} & \text { Thermo Fischer Scientific, A-11055 } & \text { AB_2534102 } \\ \text { Donkey anti-goat } & 488 & 4 \mu \mathrm{g} / \mathrm{mL} & \text { Thermo Fischer Scientific, A-11056 } & \text { AB_2534103 } \\ \text { Donkey anti-goat } & 546 & 4 \mu \mathrm{g} / \mathrm{mL} & & \end{array}$

${ }^{a}$ No information about the initial concentration available.

secondary antibody solution (0.02\% Triton X-100, 1\% BSA in PBS) for $3 \mathrm{hr}$ at room temperature. Then the sections were rinsed in PBS and followed by a nuclear staining with 4'-6-diamidin-2-phenylindol-dye (DAPI). Finally, sections were shortly washed in distilled water before being coverslipped with Fluoprep (bioMérieux, Basingstoke, UK), sealed against exsiccation and stored in dark at $4^{\circ} \mathrm{C}$ until analysis with a laserscanning confocal microscope (TCS SP2, Leica microsystems, Wetzlar, Germany). As positive controls for choline acetyltransferase (ChAT), vesicular acetylcholine transporter (VAChT) and $\alpha$-Bungarotoxin (BTX) combined with SV2, we performed staining in longitudinal and transversal sections of gerbil thigh muscle following the same procedure. All images were enhanced by adjusting the contrast and the brightness of the whole image/stack with the software ImageJ. All information about the antibodies used are specified in Table 1 (see also Section 2.4 below).

\section{3 | VAChT staining quantification}

Density, distribution and properties of VAChT-immunosignals in the AVCN were determined in an unbiased manner using custom software written in MATLAB, similar to a previous study (Goyer et al., 2015). Here, AVCN and the granule cell domain (GCD) surrounding the AVCN were outlined by the experimenter with the aid of anti-calretinin and DAPI staining in confocal sections. VAChT signals within the respective regions of interest (ROI) were then automatically detected and analyzed in binarized images using the MATLAB function bwlabel.m. The white-threshold for binarizing the images was identical (0.5) for all images and timepoints, thus the fluorescent intensity of the individual signals was not analyzed. The number of detected signals was normalized to the area of the ROls and average number of signals and mean area of individual signals was calculated. Mean area of the selected ROls was relatively constant for AVCN (P5: $0.28 \pm 0.11 \mathrm{~mm}^{2}$; P10: $0.27 \pm$ $0.07 \mathrm{~mm}^{2}$; P15: $0.32 \pm 0.04 \mathrm{~mm}^{2}$; P28: $0.28 \pm 0.05 \mathrm{~mm}^{2}$ ) and GCD
(P5: $0.09 \pm 0.01 \mathrm{~mm}^{2}$; P10: $0.06 \pm 0.02 \mathrm{~mm}^{2}$; P15: $0.08 \pm 0.01 \mathrm{~mm}^{2}$; P28: $0.07 \pm 0.02 \mathrm{~mm}^{2}$ ), ruling out bias effects caused by overall growth of the nucleus. Data was analyzed using the Kruskal-Wallis test and a post-hoc U-test with correction for repeated testing. Spatial development of cholinergic innervation of the AVCN was visualized by calculating spatial histograms of VAChT signal locations. For this, the centroid coordinates of all detected VAChT signals were normalized to the bounding box of the corresponding AVCN mask and their occurrence counted in $64(8 \times 8)$ spatial bins. From these spatial histograms, we plotted normalized "innervation density" maps with the MATLAB function contourf.m.

\subsection{Antibody characterization}

VAChT is a membrane protein that translocates acetylcholine from the cytoplasm into synaptic vesicles and a good marker for labeling cholinergic neurons (Arvidsson, Riedl, Elde, \& Meister, 1997). VAChT rabbit polyclonal antibody was purchased from Synaptic Systems (RRID: AB_887864). This antibody recognizes amino acids $475-530$ of the $C$ terminal part in the glycosylated and unglycosylated protein. WB results for VAChT (Figure 1a) were shown for boiled and nonboiled samples because this protein forms aggregates after boiling. A more obvious smeared band was revealed between 60 and 75 kDa corresponding to the molecular weight of the protein in non-boiled sample as expected. However, VAChT aggregates (around 80 and $120 \mathrm{kDa}$ ) were present even in non-boiled samples. In addition, immunoreactivity for VAChT was positively controlled using muscle tissue. VAChT was detected around muscle fibers forming a neuromuscular junction in skeletal muscle of gerbils (Figure 1b1) confirming the specificity of the antibody.

Another marker of cholinergic neurons is the enzyme that synthesizes acetylcholine ChAT. The polyclonal antibody used was raised in rabbit against the human placental ChAT and commercially available 
through Millipore (Cat\# AB143, RRID:AB_2079760). This antibody recognized strongly a double band slightly lighter than $100 \mathrm{kDa}$ corresponding to the $82.6 \mathrm{kDa}$ enzyme (Figure 1a). Unlike VAChT staining, no typical cholinergic terminals ending on muscle fiber were observed with ChAT. Nevertheless, ChAT-positive punctae were detected around muscle cells (Figure 1b2).

Calretinin, also known as calbindin 2, is an EF-hand motif calcium binding protein. Calretinin antibodies strongly stain AN terminals and spherical bushy cells (SBCs) in the CN (Bazwinsky, Härtig, \& Rübsamen, 2008). The commercial polyclonal antibody used in this study was raised in goat (Millipore Cat\# AB1550, RRID:AB_90764). This antibody showed two bands in WB (Figure 1a) with a stronger one located

a
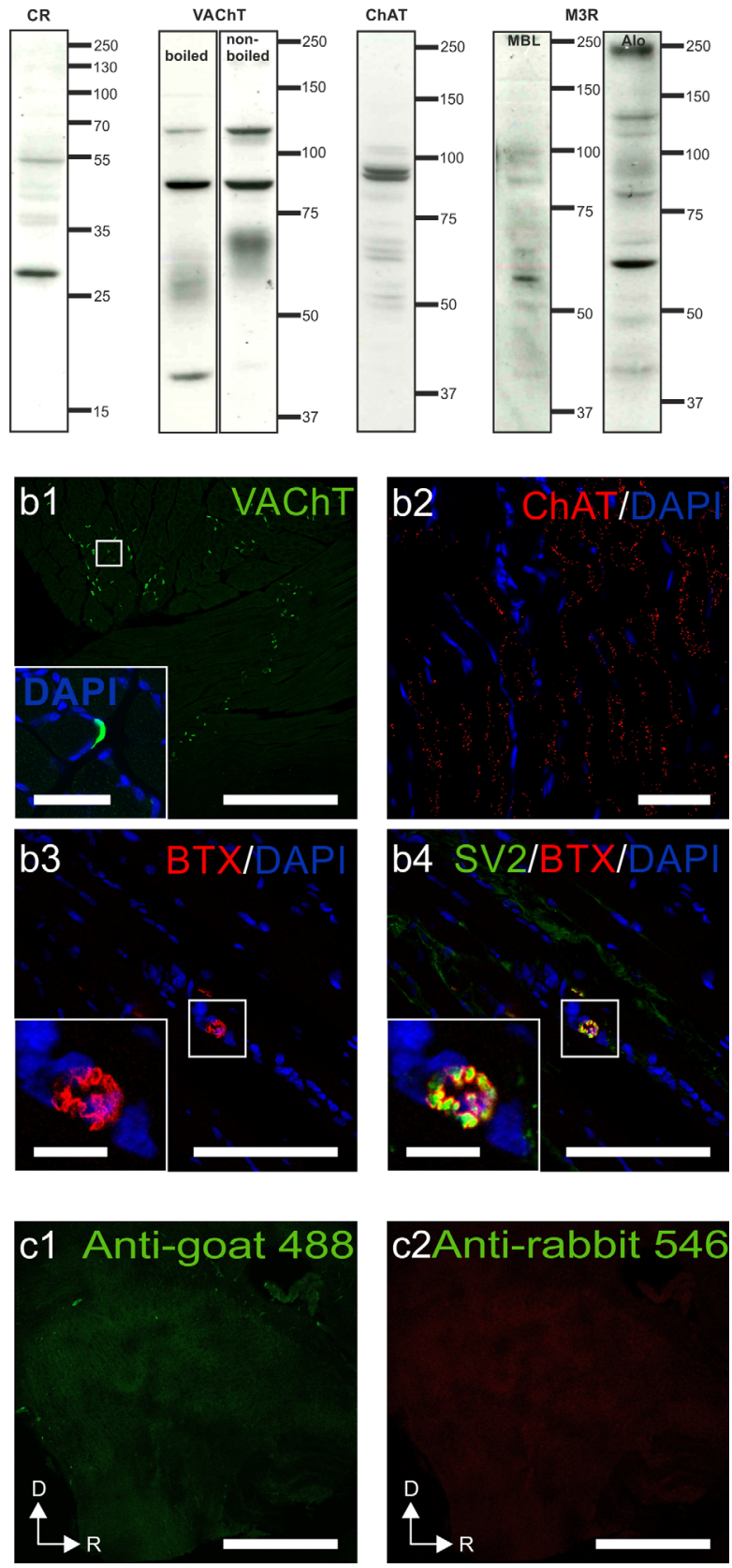

FIGURE 1. between 25 and $35 \mathrm{kDa}$ matching the molecular weight of the immunogen (31.4 kDa).

Muscarinic 3 receptor is a phospholipase C (PLC) positivelycoupled metabotropic receptor. We used two polyclonal anti-m3 muscarinic receptor (M3R) antibodies raised in rabbit, from different providers [MBL International Cat\# LS-A5259, RRID:AB_2080193 (1) and Alomone labs Cat\# AMR-006, RRID:AB_2039997 (2)], however it was difficult to obtain strong staining in gerbil brain tissue. M3R antibody (1) from MBL recognizes a synthetic peptide of 19 amino acids in the C-terminal part of human $\mathrm{m} 3$ receptor whereas (2) is targeted against the third intracellular loop of the rat receptor (461-479 amino acids). M3R antibody (2) was previously described by WB and IHC in cells of human colon (Harrington et al., 2010). A single band was also present between 50 and $75 \mathrm{kDa}$ in gerbil brainstem. A faint single band was also recognized by the other M3R antibody (1).

The secondary antibodies donkey anti-rabbit conjugated with either the fluorophore alexa488 or alexa546 and donkey anti-goat alexa488, were purchased from Thermo Fischer Scientific. Negative controls for both donkey anti-rabbit and donkey anti-goat secondary antibodies were performed by omitting the primary antibody. In both cases, no labeling stood out from the normal background (Figure 1c).

\section{$2.5 \mid \alpha$-bungarotoxin staining}

The Alexa555-conjugated $\alpha$-Bungarotoxin $(2 \mu \mathrm{g} / \mathrm{mL}$, Thermo Fischer Scientific, Cat\# B35451) is known to bind the $\alpha$-subunit of the nicotinic receptors with high affinity. The protocol used was the same as the immunohistofluorescence (see above), but the toxin was added to the secondary antibody solution. In gerbil muscle tissue (positive control), BTX-labeling of nicotinic receptors is clearly noticeable on the post-

FIGURE 1 Specificity of the antibodies and toxin used. (a) Western Blot of the primary antibodies used in the study (see Table 1). The scale on the right indicates the molecular weight in kDa. (b) Positive control of VACht and ChAT immunostaining in the gerbil muscle tissue (from the upper hind leg). Confocal image in b1 shows VAChT immunoreactivity in muscle endplate terminals and motoaxons in both transverse (upper part of the image) and longitudinal (lower part) sections of the muscle, scalebar $=500 \mu \mathrm{m}$. A single neuromuscular junction is shown in a higher magnification of the white square in the corner, scalebar $=100 \mu \mathrm{m}$. b2, ChAT signal is present in muscle but weaker than VAChT signal and does not highlight the same pattern of the presynaptic side of the neuromuscular junction but seems to stain motor axons in an intermittent manner. Scalebar $=50 \mu \mathrm{m}$. Positive control for Alexacoupled BTX staining, which labels motor endplates in red (b3) while synaptic vesicle protein 2 - positive signals show the presynaptic terminal of the motor endplate (b4), scalebar $=100 \mu \mathrm{m}$ and $15 \mu \mathrm{m}$ for higher magnification. (c) Performing the fluorescence immunohistochemistry protocol without adding the primary antibodies does not show any unspecific labeling of the secondary antibodies. Scalebar $=500 \mu \mathrm{m}$. BTX $=\alpha$-bungarotoxin; ChAT $=$ choline acetyltransferase; $C R=$ calretinin; $M 3 R=$ muscarinic 3 receptor; SV2 = synaptic vesicle glycoprotein $2 \mathrm{~A} ; \mathrm{VAChT}=$ vesicular acetylcholine transporter. Section orientation: $\mathrm{D}=$ dorsal; $\mathrm{R}=$ rostral [Color figure can be viewed at wileyonlinelibrary.com] 

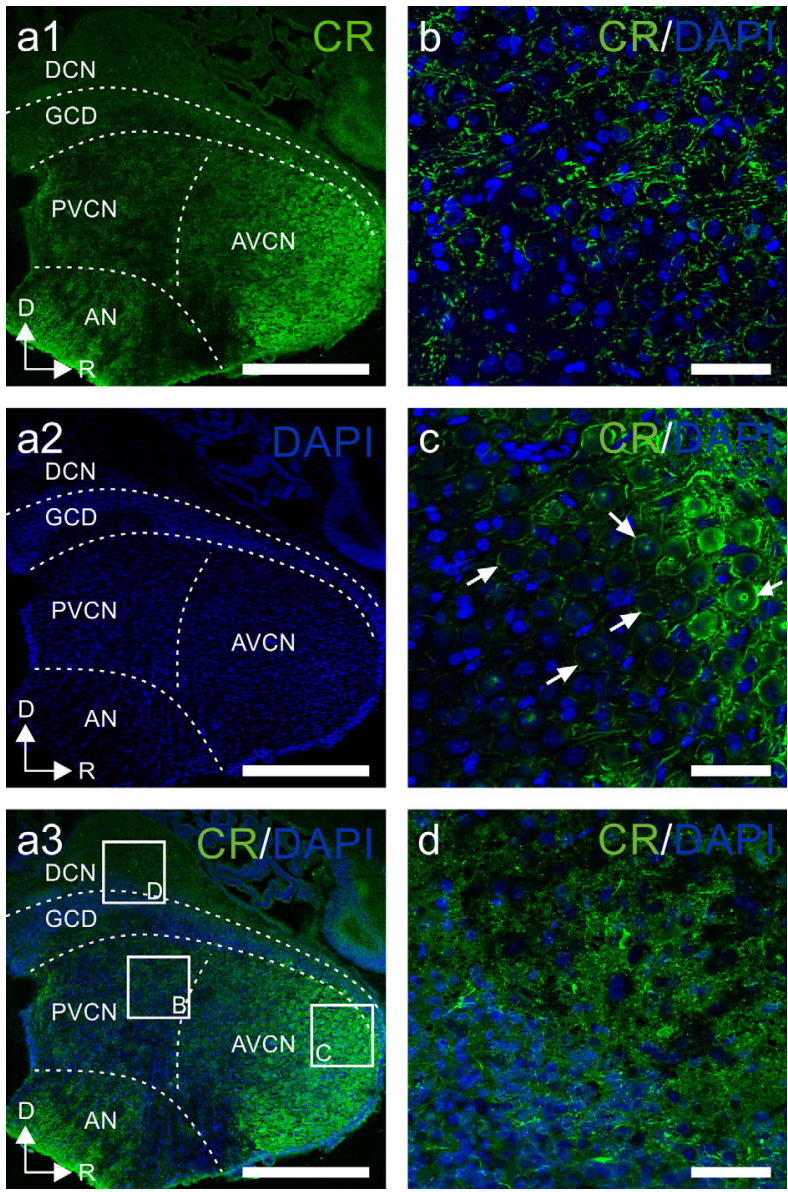

FIGURE 2 Definition of cochlear nucleus subdivisions. (a) Confocal images of P16 gerbil cochlear nucleus in parasagittal plane delineating (white dashed lines) the subdivisions of the $\mathrm{CN}$ with staining for calretinin (a1), DAPI (a2) and merged (a3), scalebar $=500 \mu \mathrm{m}$. PVCN, AVCN and DCN delimited by white squares in a3 are magnified in (b), (c) and (d) respectively, scalebar $=50 \mu \mathrm{m}$. (b) Cells receive multiple modified endbulb terminals in PVCN, which are larger than bouton-synapses. (c) In the AVCN, calretinin-positive signal stains the typical large AN endings, so called endbulb of Held (arrows) and labels a sub-population of spherical bushy cells. (d) The granule cell domain is noticeable by a high density of nuclei in the lower left compared to the DCN on the upper right, both GCD and DCN receive calretinin-positive bouton-synapses from the $\mathrm{AN}$. $\mathrm{AN}=$ auditory nerve;

$A V C N=$ anteroventral part of the cochlear nucleus; $C R=$ calretinin $\mathrm{DCN}=$ dorsal part of the cochlear nucleus; $\mathrm{PVCN}=$ posteroventral part of the cochlear nucleus. Section orientation: $\mathrm{D}=$ dorsal; $\mathrm{R}=$ rostral [Color figure can be viewed at wileyonlinelibrary.com]

synaptic side of neuromuscular junction (Figure $1 \mathrm{~b} 3$ ), confirmed by the apposition of the immunoreactivity for SV2 (Figure 1b4), a synaptic vesicle glycoprotein (anti-SV2 antibody, $0.74 \mu \mathrm{g} / \mathrm{mL}$ from DSHB Cat\# SV2, RRID:AB_2315385).

\subsection{Acute slice preparation}

Gerbils aged from P14 to P19 were deeply anesthetized with isoflurane and decapitated. The brain was quickly removed from the skull and dissected in ice-cold cutting buffer containing (in mM): 215 sucrose, 10 glucose, $2.5 \mathrm{KCl}, 4 \mathrm{Mg}_{2} \mathrm{Cl}, 1.25 \mathrm{NaHPO}_{4}, 25 \mathrm{NaHCO}_{3}, 3 \mathrm{C}_{6} \mathrm{H}_{12} \mathrm{O}_{6}$ (myoinositol), $2 \mathrm{C}_{3} \mathrm{H}_{3} \mathrm{NaO}_{3}$ (sodium pyruvate), $0.5 \mathrm{C}_{6} \mathrm{H}_{8} \mathrm{O}_{6}$ ( $\mathrm{L}$ ascorbic acid), bubbled with $95 \% \mathrm{O}_{2}$ and $5 \% \mathrm{CO}_{2}$ to a $\mathrm{pH}$ of 7.4 (308 mOsm). Acute frontal slices $(200-250 \mu \mathrm{m})$ containing the rostral part of AVCN were cut with a vibrating microtome (VT1200S, Leica Biosystems, Nussloch, Germany). The slices were then incubated at room temperature for at least 45 min before recording in ACSF containing (in mM): $125 \mathrm{NaCl}, 2.5 \mathrm{KCl}$, $1 \mathrm{MgCl}_{2}, 2 \mathrm{CaCl}_{2}, 1.25 \mathrm{NaH}_{2} \mathrm{PO}_{4}, 2.5 \mathrm{NaHCO}_{3}, 10$ glucose, $3 \mathrm{C}_{6} \mathrm{H}_{12} \mathrm{O}_{6}$ (myo-inositol), $2 \mathrm{C}_{3} \mathrm{H}_{3} \mathrm{NaO}_{3}$ (sodium pyruvate), $0.5 \mathrm{C}_{6} \mathrm{H}_{8} \mathrm{O}_{6}$ ( $\mathrm{L}$ ascorbic acid) bubbled with $95 \% \mathrm{O}_{2}$ and $5 \% \mathrm{CO}_{2}$ to a pH of 7.4 (314 mOsm).

\section{7 | Electrophysiology}

After incubation, the acute slices were placed into a recording chamber and perfused with ACSF at around $100 \mathrm{~mL} / \mathrm{hr}$ under a fixed-stage
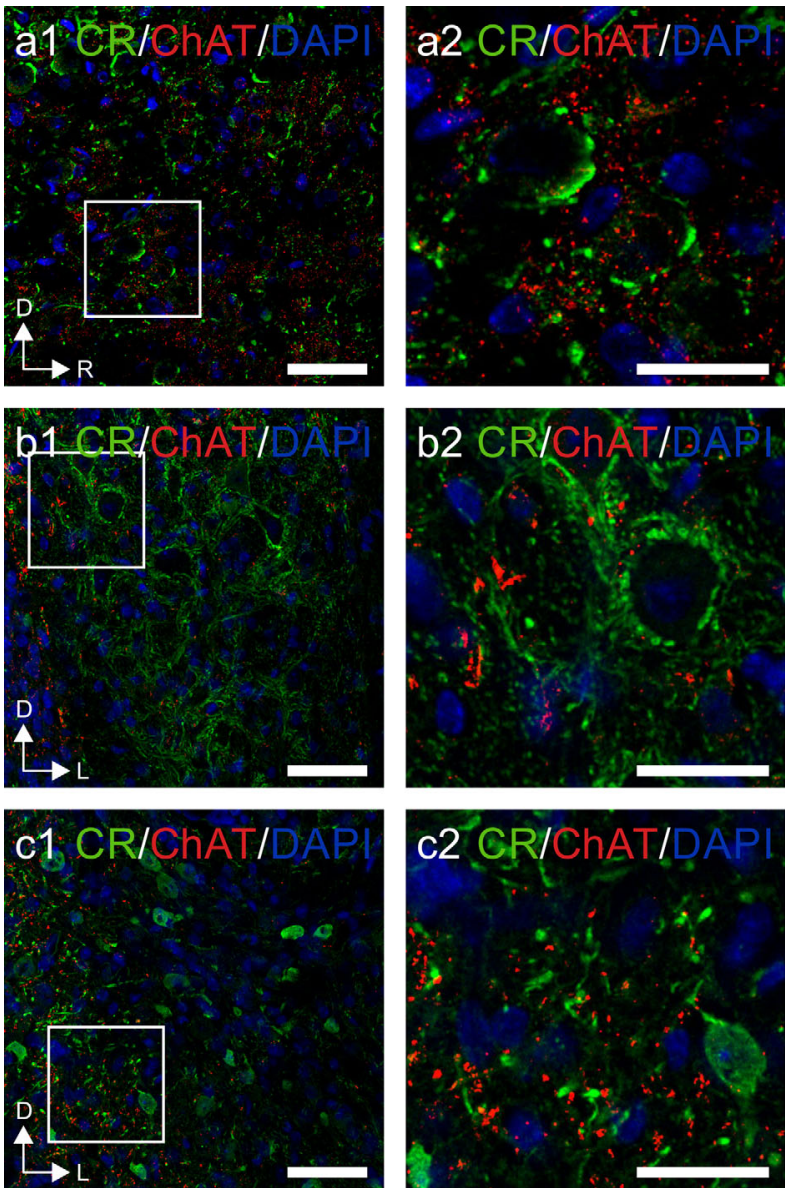

FIGURE 3 ChAT staining in gerbil cochlear nucleus. (a-c) Confocal images with double immunostaining for ChAT and CR in AVCN (a), PVCN (b) and DCN (c) of P18 gerbil brain. Sparse signals for ChAT are visible in all subdivisions of the cochlear nucleus in the neuropil between principal neuron cell bodies (a1, b1, c1, scalebar $=25 \mu \mathrm{m}$ ). (a2), (b2), (c2) higher magnifications (scalebar $=50 \mu \mathrm{m}$ ) of the white squares allow to see better the weak ChAT labeling, for example in (a1), in close proximity of identifiable SBCs by their large calretininpositive inputs. $\mathrm{AN}=$ auditory nerve; $\mathrm{AVCN}=$ anteroventral part of the cochlear nucleus; ChAT = choline acetyltransferase; $C R=$ calretinin. Section orientation: $\mathrm{D}=$ dorsal; $\mathrm{L}=$ lateral; $\mathrm{R}=$ rostral [Color figure can be viewed at wileyonlinelibrary.com] 
microscope with IR-DIC and fluorescent imaging (Nikon Eclipse FN-1 microscope equipped with DS-Qi1MC camera and DC-U3 camera controller, Nikon Instruments, Japan). SBCs were recorded in the wholecell configuration under visual control with a HEKA EPC10 USB double patch clamp amplifier, controlled with HEKA PATCHMASTER software (HEKA Elektronik Dr. Schulze GmbH, Lambrecht/Pfalz, Germany). Recordings were low-pass filtered at $2.7 \mathrm{kHz}$ and sampled at $50 \mathrm{kHz}$. All data are presented without correcting the junction potential, which was estimated to be $-11 \mathrm{mV}$. Recording pipettes were pulled from borosilicate glass filament electrodes (Science Products $\mathrm{GmbH}$, Hofheim, Germany) with a horizontal Zeitz-DMZ-Universal-Puller (Zeitz Instruments, Martinsried, Germany) to have a resistance of 3.7-4.7 $\mathrm{M} \Omega$ when filled with the recording solution. For general characterization of bushy cells (shown in Figure 4d,e) a gluconate-based internal solution containing (in mM) $100 \mathrm{~K}$-gluconate, $40 \mathrm{KCl}, 0.1 \mathrm{CaCl}_{2}, 10 \mathrm{HEPES}, 1.1$ EGTA, 2 Mg-ATP, 0.4 GTP, 0.1 Alexa-488 hydrazide (Thermo Fischer
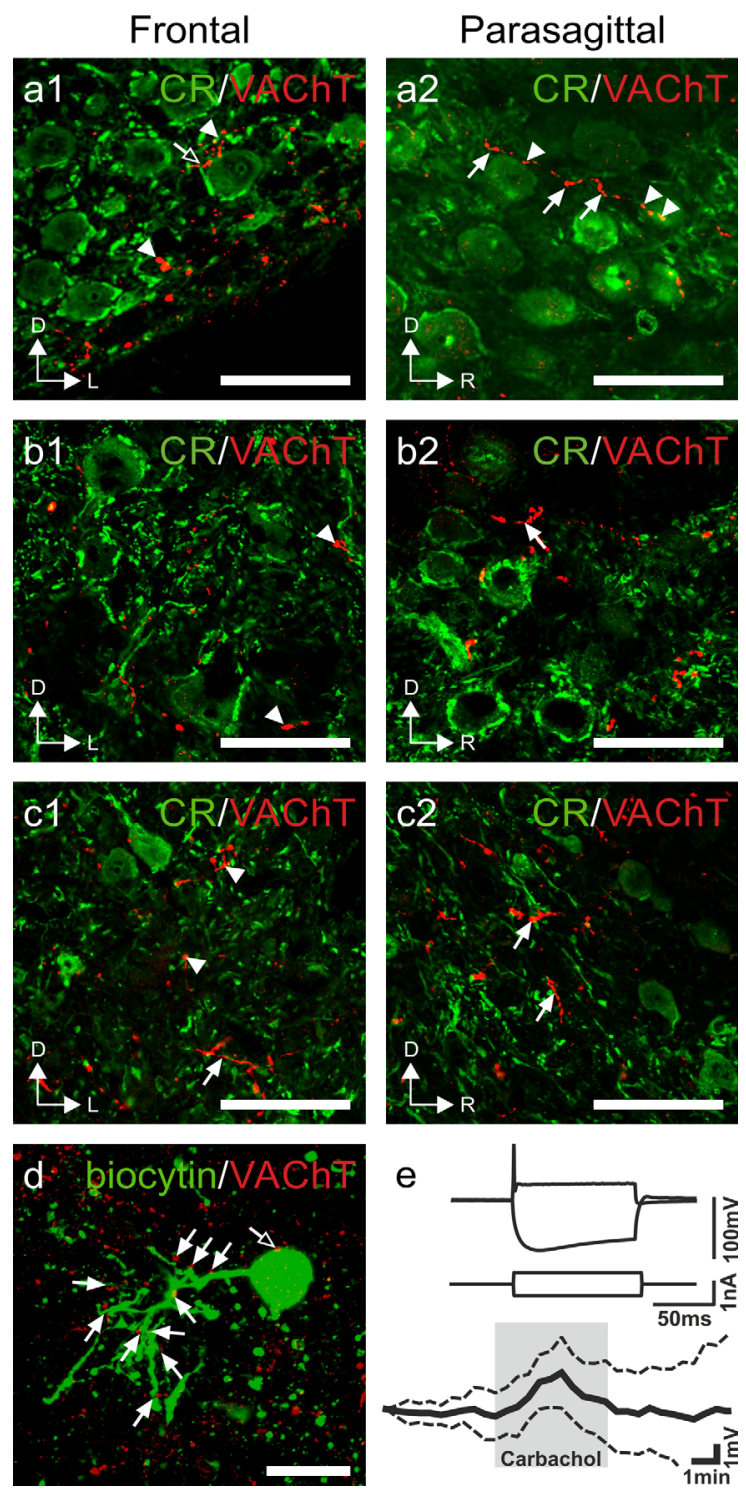

FIGURE 4.
Scientific), $3 \mathrm{mg} / \mathrm{mL}$ biocytin (Thermo Fischer Scientific) was used, adjusted to a pH of 7.2 with $1 \mathrm{M} \mathrm{KOH} \mathrm{(280} \mathrm{mOsm).}$

\section{8 | Double biocytin-streptavidin/VAChT staining of spherical bushy cells}

After recordings, the slices were fixed in PFA overnight before being stored at $4^{\circ} \mathrm{C}$ in PBS until further stainings. After washing $2 \times 5$ min in PBS, the slices were incubated in a blocking solution (4\% NHS, $0.4 \%$ Triton X-100, 1\% BSA in PBS) for $3 \mathrm{hr}$. Then the blocking solution was replaced by the primary antibody solution containing VAChT antibody (1\% NHS, 0.3\% Triton X-100, 1\% BSA in PBS) for $24 \mathrm{hr}$ at $4^{\circ} \mathrm{C}$. Next, the slices were rinsed first in PBS $6 \times 5$ min, second in PBS with $0.3 \%$ Triton X-100. The slices were then treated with the streptavidin solution (0.1\% Triton X-100, 1\% BSA in PBS, 1:800 Alexa Fluor ${ }^{\circledR}$ dye streptavidin conjugates, Thermo Fischer Scientific, Darmstadt, Germany, Cat\# S11223) containing also the secondary antibody for $2.5 \mathrm{hr}$ at room temperature. Next, the slices were washed $6 \times 5$ min with $0.3 \%$ Triton X-100 in just Tris Buffered Saline (TBS) following by $3 \times 5$ min washing in TBS. Additionally, the slices were incubated with DAPI for $5 \mathrm{~min}$. Finally, the slices were rinsed $2 \times 5 \mathrm{~min}$ in $0.1 \mathrm{M}$ PB. Secure Seal adhesive sheets $(18 \times 18 \times 0.24 \mathrm{~mm}$, Grace Bio-Labs, Bend, Oregon) were holed (square-shaped) in the middle and pasted on big coverslips $(24 \times 60 \mathrm{~mm})$. The slices were mounted on the coverslip in the middle on the Secure Seal adhesive sheet and covered with a small coverslip $(18 \times 18 \mathrm{~mm})$ after applying a drop of Fluropep (bioMérieux, Basingstoke, UK). The pasted-coverslips were then placed on a glass slide and scanned with a laser-scanning confocal microscope (TCS SP2, Leica microsystems, Wetzlar, Germany).

FIGURE 4 VAChT staining in gerbil cochlear nucleus. (a-c) Double immunostaining for calretinin and VAChT in P28-31 gerbil cochlear nucleus. Filled arrows and arrowheads point out VAChT-positive fibers and punctate signal respectively, whereas open arrows show apposition of VAChT positive signal to soma. Scalebar $=50 \mu \mathrm{m}$. (a) VAChT-positive punctate signal observed in the vicinity to the SBCs closest to the granule cell layer in frontal section (a1). Punctate signal and cholinergic fibers were revealed in parasagittal section of AVCN (a2). (b) PVCN also showed VAChT-positive labeling mostly seen as punctate in a frontal section (b1) and fibers in parasagittal plane (b2). (c) VAChT-positive immunoreactivity was also present in both frontal (c1) and parasagittal (c2) DCN section. (d) Z-projection of confocal stack from rostral section of AVCN of one SBC filled with biocytin during intracellular recordings and then incubated with anti-VAChT antibody, scalebar $=25 \mu \mathrm{m}$. (e) The cell shown in (d) responded with a phasic action potential at the beginning to the application of depolarizing current and exhibit a characteristic voltage sag to hyperpolarizing current, scalebars $=25 \mathrm{~ms}$; $20 \mathrm{mV} / 0.5 \mathrm{nA}$ (upper part). SBC $(\mathrm{n}=5)$ responded to bath application of carbachol with a slow depolarization of the resting membrane potential (lower part). AVCN = anteroventral part of the cochlear nucleus; $\mathrm{CR}=$ calretinin; $\mathrm{DCN}=$ dorsal part of the cochlear nucleus; $\mathrm{SBC}=$ spherical bushy cell; $\mathrm{PVCN}=$ posteroventral part of the cochlear nucleus; VAChT = vesicular acetylcholine transporter. Section orientation: $\mathrm{D}=$ dorsal; $\mathrm{L}=$ lateral; $\mathrm{R}=$ rostral [Color figure can be viewed at wileyonlinelibrary.com] 


\section{3 | RESULTS}

In the present study, a total of 29 Mongolian gerbils aged P5 to P31 were used to elucidate the development and cellular localization of the cholinergic innervation of the $\mathrm{CN}$. For this, we defined the subdivisions of the $\mathrm{CN}$ of the gerbil by means of immunostaining for calretinin and DAPI, exploiting the fact that AN afferents and a subset of principal neurons are strongly positive for calretinin (Bazwinsky et al., 2008). Those subdivisions are shown in Figure 2 in a parasagittal plane of a $\mathrm{P} 16$ gerbil. The PVCN and (AVCN were delineated by the entrance of the AN ventrally (Figure 2a). In addition to this boundary, the AVCN could be distinguished from the PVCN by the pattern of immunoreactivity for calretinin (Figure 2a). Even though enlarged calretinin-positive nerve terminals and immunopositive cells were also observed in higher magnification of PVCN (Figure 2b), this was not comparable to the strong labeling of neurons and the distinct giant AN terminals, so called endbulbs of Held (indicated by arrows in Figure 2c) in the AVCN. The DCN, which is a layered structure and shows small AN boutons in the calretinin staining, is separated from the VCN by the granule cell domain (GCD), which is easily noticeable in DAPI staining by its high density of small nuclei (Figure 2a2,d). A fine layer of granule cells extending from GCD surrounds the whole VCN (Figure 2a2). In every section shown below, staining against calretinin (in green) and DAPI staining (in blue, sometimes omitted for clarity) was performed in order to identify each subdivision of the $\mathrm{CN}$ as explained above.

\section{1 | Cholinergic system sends projections throughout the cochlear nucleus}

To assess the cholinergic innervation of each subdivision of the $\mathrm{CN}$, immunohistochemical staining was performed in frontal and parasagittal sections containing the $\mathrm{CN}$ of hearing gerbils aged from P18 to P31. In combination with calretinin and DAPI staining, antibodies targeting either the choline acetyltransferase (ChAT) or the vesicular acetylcholine transporter (VAChT) were used.

Immunoreactivity for ChAT appeared as sparse puncta in the neuropil of the entire $\mathrm{CN}$ (Figure 3, red immunoreactivity) including in the vicinity of timing-coding principal neurons in the AVCN (spherical bushy cells), identified by their giant calretinin-positive AN inputs (Figure 3a). ChAT labeling showed strong intensity in caudal PVCN (Figure $3 \mathrm{~b})$, where octopus cells are located, and was also present around other cell types in the deep layer of DCN (Figure 3c). However, the exact cell subtype could not be clearly determined only based on these stainings. No clear cholinergic fiber or terminal labeling was observed with the ChAT antibody, as was confirmed in control muscle tissue as well (cf. Figure 1b2). Considering this, we also used an antibody against VAChT, which reliably labels neuromuscular cholinergic terminals, as shown in Figure 1b1. VAChT immunoreactivity was revealed as sparse puncta in the neuropil in every part of the $\mathrm{CN}$ (Figure 4) similar to the staining for ChAT. The average area of the punctae (measured in P28 AVCN, see following section and Figure 6) was $0.93 \pm 0.08 \mu \mathrm{m}^{2}$, about $5 \%$ of the signals were $>2.5 \mu \mathrm{m}^{2}$ and $1 \%$ of the signals had even larger area $\left(>5.2 \mu \mathrm{m}^{2}\right)$ in some cases reaching almost $20 \mu \mathrm{m}^{2}$. We therefor interpreted these punctate signals as cross-sections of both cholinergic axons and of VAChT-positive axonal swellings or varicosities. Interestingly, punctate reactivity appeared especially concentrated in the granule cell layer in sections containing rostral AVCN (indicated by arrowheads in Figure 4a1), unlike ChAT staining. In addition, VAChT staining revealed immunopositive fibers running among principal neurons (filled arrow) and forming en-passant swellings in the neuropil of these cells (arrowheads) in parasagittal sections of AVCN (Figure 4a2). Punctate reactivity (arrowheads) was systematically observed in the frontal plane also for PVCN (Figure 4b1) and DCN (Figure 4c1). Rarely, short stretches of VAChT-positive fiber (arrow) were seen. Fibers were most reliably revealed in parasagittal sections (Figure 4a2,b2,c2). Taken together, VAChT-positive fibers were particularly visible in parasagittal sections whereas punctate reactivity was shown in frontal sections in each subdivision, suggesting that cholinergic fibers ran in a caudorostral direction throughout the $\mathrm{CN}$. In a few cases, cholinergic reactivity was detected in contact with the soma of principal neurons (Figure 4a1,d, open arrows).

From our staining against VAChT two questions arose: do cholinergic terminals in the neuropil indeed contact dendrites of principal neurons? Do neurons whose dendrites show close spatial proximity to VAChT-positive terminals actually respond to cholinergic signaling? To answer these questions, we focused on the spherical bushy cells (SBC) of the AVCN, because these neurons are clearly identifiable with our experimental approaches. In vitro, whole-cell recordings were made with a gluconate-based internal solution containing biocytin. Neurons were physiologically identified as SBC and their responsivity to acetylcholine was confirmed. SBC located in the rostral part of the AVCN (in P16 or older gerbils) generally presented a typical phasic and sharp action potential as well as a sag in response to hyperpolarizing stimuli (Figure 4e, upper part) and can thus be distinguished from stellate cells, which are also present in the AVCN. We confirmed cholinergic responsivity of SBC by wash-in of carbachol, an agonist of both nicotinic and muscarinic acetylcholine receptors. As shown before by us (Goyer et al., 2016), SBC responded to carbachol (and other cholinergic compounds) with a slow, transient change of the resting membrane potential (Figure 4e, lower panel; $2.6 \pm 2.4 \mathrm{mV}, n=5$ neurons that were also stained against VAChT) over several minutes. This effect was statistically significant (ANOVA $p<.05$; post-hoc Tukey test $p<.05$ vs. both control and recovery period). Overall, $71 \%$ of recorded neurons (32/ 45) showed a response to various cholinergic agonists and antagonists in this set of experiments. VAChT immunoreactivity was observed in the dendritic field around recorded SBC, including punctate reactivity in apposition of the bushy dendrite. Since we interpret the VAChTpositive punctae partially as axonal swellings, these results are suggestive of cholinergic dendritic terminals (closed arrows Figure 4d). Fewer cholinergic punctae were found in apposition with the somatic membrane (open arrow in Figure 4d).

Altogether, our immunohistochemical data suggest that cholinergic axons projected to the entire $\mathrm{CN}$, most likely in a caudo-rostral direction and sparsely innervated the neuropil surrounding $\mathrm{CN}$ principal neurons. For the AVCN we specifically showed that VAChT positive axon terminals predominantly targeted the dendritic field of timing- 

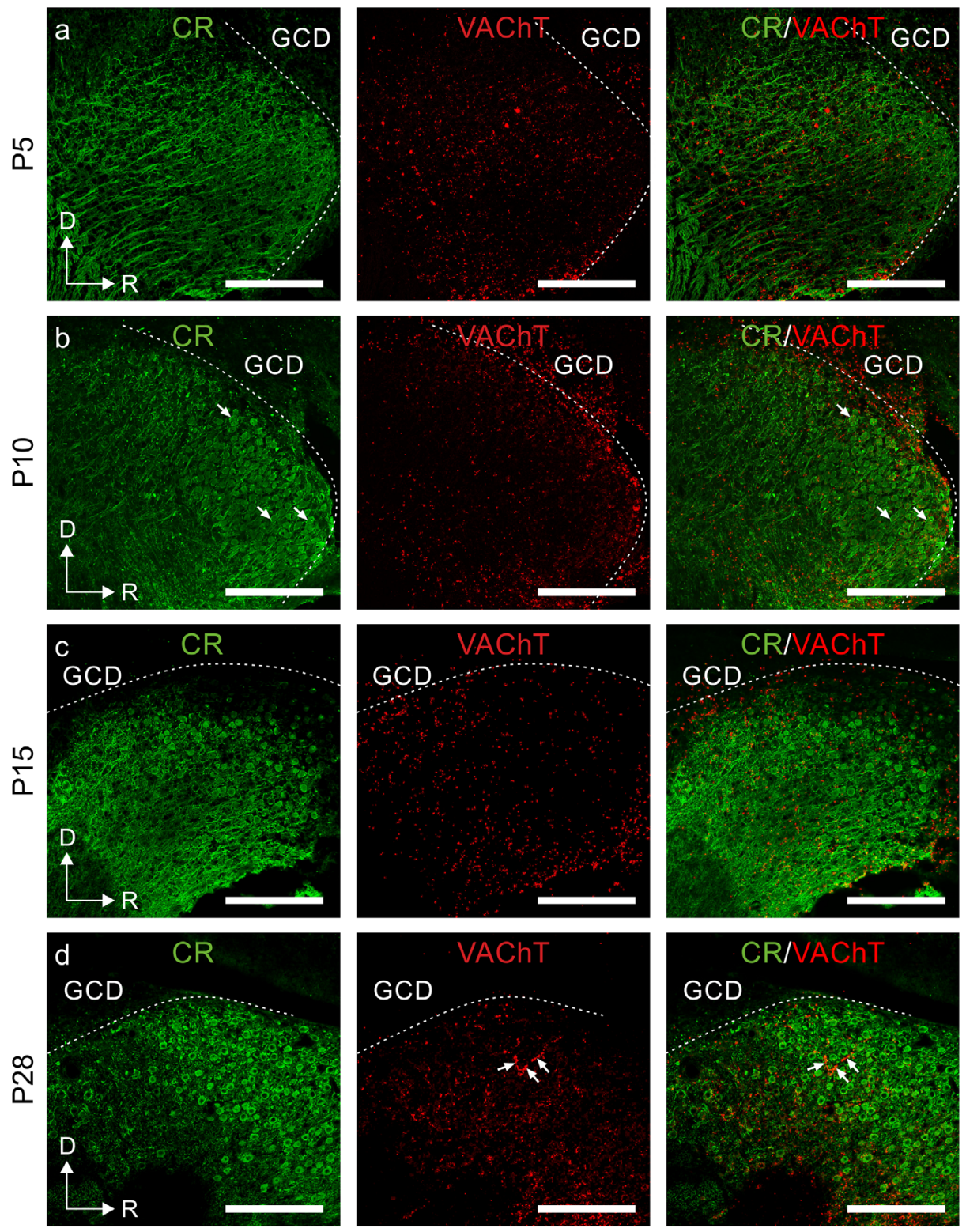

FIGURE 5 Development of AN terminals and cholinergic innervation in the AVCN and GCD. (a-d) Double immunostaining for calretinin (left) and VAChT (middle), merged (right) in AVCN sections of P5 (a), P10 (b), P15 (c) and P28 (d) gerbil brains. (a) Before hearing onset, AN innervation was not completely mature but VAChT signal was already present in both AVCN and GCD, albeit weak. (b) Few enlarged AN terminals, early endbulbs of Held (indicated by arrows) were observed at P10. VAChT signal was weakly present in both regions. (c) After hearing onset (P15) the innervation pattern of the AVCN began to appear normal, density and intensity of VAChT immunosignals were clearly increased. (d) At P28, endbulbs of Held appear mature and VAChT-positive fibers were clearly distinguishable in the AVCN (arrows). Scalebar $=250 \mu \mathrm{m}$. AVCN = anteroventral part of the cochlear nucleus; CR = calretinin; GCD = granule cell domain; VAChT = vesicular acetylcholine transporter. Section orientation: $\mathrm{D}=$ dorsal; $\mathrm{R}=$ rostral [Color figure can be viewed at wileyonlinelibrary.com]

coding spherical bushy cells which are responsive to cholinergic stimulation.

\section{2 | Cholinergic innervation of the AVCN progresses from medial to lateral during development}

To evaluate how the cholinergic innervation of the AVCN and the GCD surrounding the AVCN proceeds during development, calretinin and VAChT staining were performed in frontal cryosections containing AVCN (Figure 5) at key developmental stages for the auditory brainstem: early postnatal (P5), before (P10) and after hearing onset (P15), and young-adult animals (P28). Hearing onset in the Mongolian gerbil occurs at P12 (cf. Smith \& Kraus, 1987).

Well before hearing onset (P5), AN fibers were already present, running with a stripe-like pattern in a rostro-caudal direction in the AVCN. However, large axo-somatic terminals were not found at this stage, indicating that AN terminals were still immature at this point in development (Figure 5a, left). This was expected, based on studies performed in the mouse (Limb \& Ryugo, 2000). VAChT immunoreactivity was present in both GCD and AVCN, but the density of punctae was 

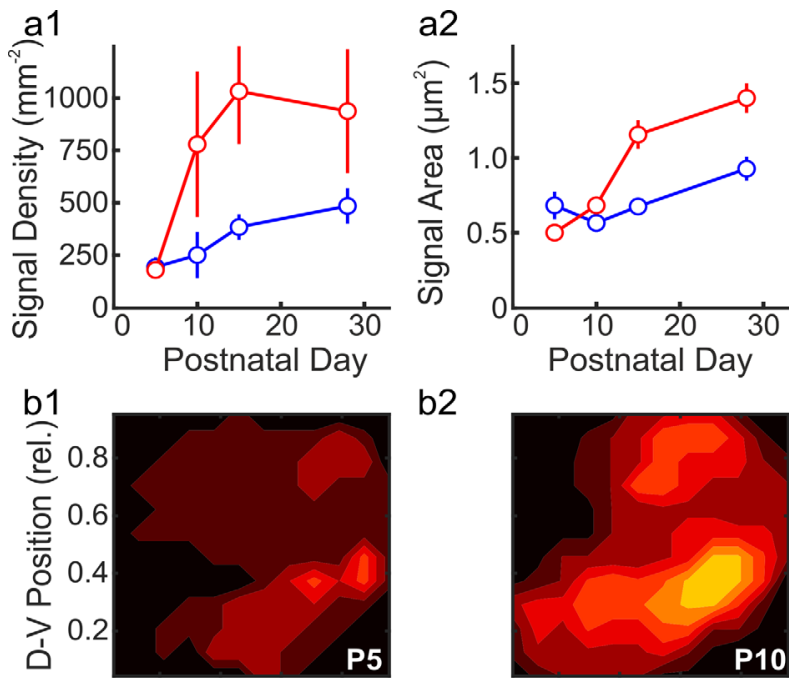

b2
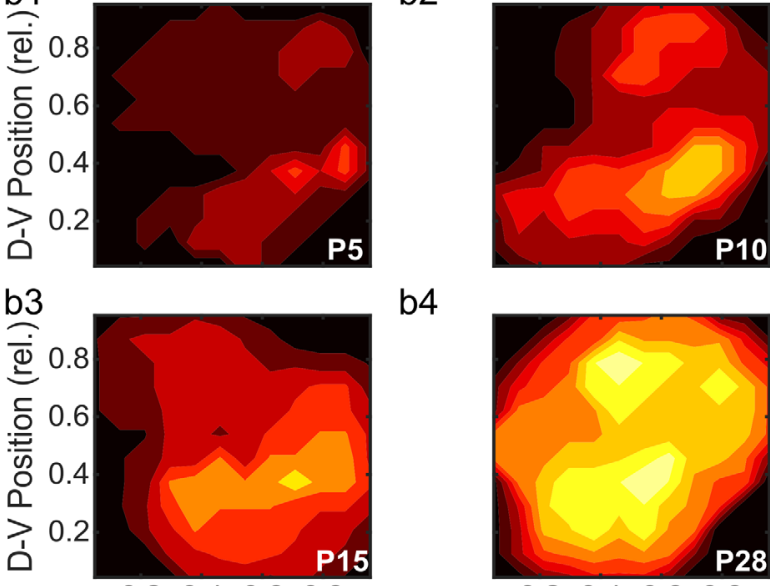

b4

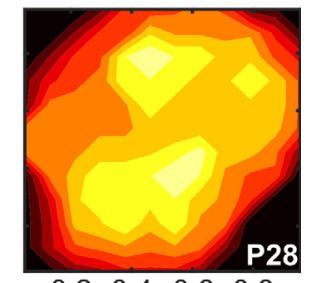

$\begin{array}{llll}0.2 & 0.4 & 0.6 & 0.8\end{array}$ M-L Position (rel.)

\section{\begin{tabular}{llll}
60 & 40 & 20 & 0 \\
\hline &
\end{tabular} \\ Mean Local Density $\left(\mathrm{mm}^{-2}\right)$}

FIGURE 6 Quantification of the development of cholinergic innervation of AVCN. (a) Quantification of the increase in average VAChT immunosignal density (a1) and size (a2) in AVCN (blue line $\&$ circles) and the GCD surrounding the AVCN (red line \& markers). Asterisk indicates significant difference $(p<0.05)$ in post-hoc $U$ test following Kruskal-Wallis Test. (b) Normalized maps of the cholinergic innervation density in the AVCN along development, constructed from spatial histograms of VAChT signal occurrence. Plots represent the left AVCN in the frontal plane (lateral left, dorsal up). Heat of color signifies relative density of VAChT signals from none (black) to highest (white) [Color figure can be viewed at wileyonlinelibrary.com]

low and the punctae appeared smaller (Figure 5a, middle) than in the adult animals. At P10, around hearing onset, calretinin-positive AN terminals were clearly visible and the stripe-like staining pattern in the AVCN was less pronounced (Figure 5b, left). At this time VAChT staining became denser in an area adjacent to the GCD (dashed lines, Figure $5 \mathrm{~b}$, middle) and in proximity to more mature AN terminals (Figure $5 \mathrm{~b}$, right). At P15, more AN giant somatic terminals on SBCs became visible (Figure $5 \mathrm{c}$, left) and the density of VAChT-positive reactivity further increased, with highest density still around the perimeter of the nucleus. The fully developed AVCN could be observed at P28 (Figure $5 \mathrm{~d}$, left). According to anatomical studies in the mouse (Limb \& Ryugo, 2000) and physiological recordings in the gerbil (Woolf \& Ryan, 1985), AVCN function and anatomy is expected to be very close to the adult stage at that age. Immunoreactivity for VAChT was the strongest at this age (Figure $5 \mathrm{~d}$, middle), where stretches of cholinergic fibers with

putative en-passant terminals could be routinely seen (arrows in Figure $5 d)$. Now central as well as peripheral parts of the AVCN were also clearly innervated with VAChT-positive fibers. These data showed that the development of the cholinergic innervation of the AVCN appeared temporally aligned with the maturation of $A N$ innervation. Furthermore, cholinergic innervation became denser first around the perimeter of the nucleus, in proximity of the GCD. However, later in development, cholinergic fibers also clearly invaded the core of the AVCN.

In order to test our qualitative observation, we quantified the development of the cholinergic innervation, focusing again on the AVCN and its surrounding GCD. We analyzed the punctate VAChT immunostaining as a proxy for cholinergic axonal innervation. For this, we used an unbiased approach (Goyer et al., 2015) employing custom image analysis software written in MATLAB that detected and analyzed shapes and number of individual immunosignals from binarized images. We detected and analyzed VAChT-immunoreactivity in at least nine confocal sections in the frontal plane per postnatal day, from a total of 12 brains $(N=3$ per data point). In line with the qualitative observations (Figure 5), the density of VAChT-immunoreactivity increased with development (Figure 6a1) in both the AVCN and the GCD around the AVCN. This was statistically significant for the AVCN (Kruskal-Wallis $\chi^{2}=13.25, d f=39$, $p<.05)$, where the density of VAChT-immunoreactivity increased from $195 \pm 46 \mathrm{~mm}^{-2}$ signals at P5 to $487 \pm 85 \mathrm{~mm}^{-2}$ signals at P28 (posthoc U-test: $p<.05)$. Density of VAChT-immunoreactivity also increased significantly (Kruskal-Wallis $\chi^{2}=10.2, d f=39, p<.05$ ) in the GCD (P5: $181 \pm 36 \mathrm{~mm}^{-2}$ vs. P28: $939 \pm 295 \mathrm{~mm}^{-2}$; post-hoc $U$-test: $p<.05$ ). VAChT-immunoreactivity significantly increased in size (Figure 6a2) in the both AVCN and GCD with development (AVCN: Kruskal-Wallis $\chi^{2}=12.9, d f=39, p<.05 ; \mathrm{GCD}:$ Kruskal-Wallis $\chi^{2}=28.5, d f=39$, $p<.001$ ). Mean area of immunoreactive punctae in the GCD increased from $0.5 \pm 0.04 \mu \mathrm{m}^{2}$ at P5 to $1.4 \pm 0.09 \mu \mathrm{m}^{2}$ at P28. In the AVCN on the other hand, VAChT-positive punctae had a slightly smaller mean signal area (P5: $0.6 \pm 0.09 \mu \mathrm{m}^{2}$ vs. P28: $0.9 \pm 0.08 \mu \mathrm{m}^{2}$ ).

We described above that, not only the overall amount but also the distribution of VAChT-immunoreactivity within the nucleus changed with development (cf. Figure 5). In order to analyze this in an unbiased manner, we constructed normalized density maps of the cholinergic innervation of the AVCN from the same dataset (Figure 6b). These maps can be interpreted as 2D-histograms of the number of occurrences of cholinergic punctae in spatial bins. For this, coordinates of cholinergic punctae were translated into relative coordinates normalized to the borders of the nucleus (lateral edge $=0$, medial edge $=1$, ventral edge $=0$, dorsal edge $=1$ ). This allowed a comparison of the relative spatial distribution of cholinergic innervation in spite of the changes of size and shape of the AVCN, which occured in parallel.

At P5, the highest density of VAChT-positive punctae was located at the medio-ventral border of the AVCN (Figure 6b1), sparing central and lateral parts of the nucleus. By P10, the highest density of immunopositive punctae was still located at the medial border of the nucleus, however occurrence of punctae started to spread along the perimeter of the nucleus (Figure 6b2) toward lateral areas. This trend became more noticeable after the onset of hearing (P15; Figure 6b3): all parts of the nucleus, including the central and lateral areas, now showed 

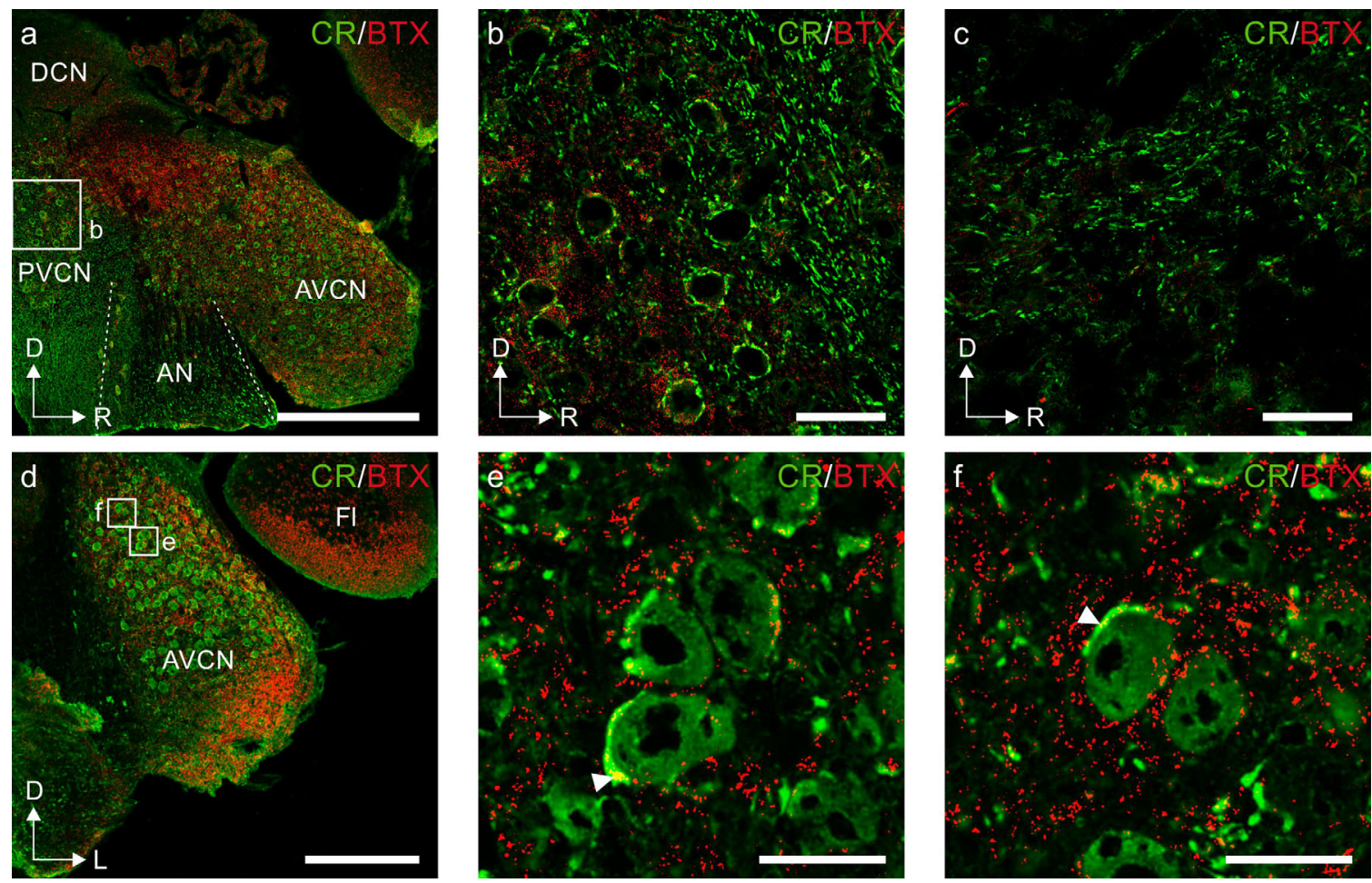

FIGURE 7 Nicotinic receptors in gerbil cochlear nucleus. (a-c) In parasagittal sections Alexa555-conjugated BTX showed dense staining in AVCN, sparse staining in PVCN, even weaker staining in DCN and none at the level of the AN. (b) Higher magnification of PVCN (white box in (a)). (c) High magnification image of DCN (separate section). Scalebars = (a) $500 \mu \mathrm{m}$, (b, c) $50 \mu \mathrm{m}$. (d-f) Frontal sections containing AVCN showed BTX signal in the neuropil around SBCs but also directly localized on endbulbs of Held (arrowheads). (e, f) show higher magnifications of the corresponding white boxes in (d). Scalebars = (d) $250 \mu \mathrm{m}$, (e, f) $25 \mu \mathrm{m}$. AN = auditory nerve; AVCN=anteroventral part of the cochlear nucleus; BTX $=\alpha$-bungarotoxin; $\mathrm{CR}=$ calretinin; $\mathrm{DCN}=$ dorsal part of the cochlear nucleus; $\mathrm{FI}=$ flocculus; $\mathrm{PVCN}=$ posteroventral part of the cochlear nucleus. section orientation: $\mathrm{D}=$ dorsal; $\mathrm{L}=$ lateral; $\mathrm{R}=$ rostral [Color figure can be viewed at wileyonlinelibrary. com]

VAChT-positive punctae, with the medial border being most densely innervated. This pattern is similar to cholinergic innervation patterns reported by other authors in the VCN of rodents (Ryan et al., 1990; Brown \& Vetter, 2009; Baashar et al., 2015). Finally, however, in P28 animals all parts of the AVCN showed strong occurrence of VAChTpositive punctae (Figure $6 \mathrm{~b} 4$ ), with the highest density now located closer to the core of the AVCN towards the latero-ventral side of the AVCN.

Taken together, from our analysis of the spatial distribution of VAChT-positive punctae we postulate a medial to lateral and peripheral to central progression of the development of cholinergic innervation of the AVCN. No part of the AVCN appeared devoid of cholinergic innervation in young adult animals. Furthermore, cholinergic innervation clearly intensified around and after the onset of hearing. Thus, we conclude that in all tonotopic parts of the AVCN (and the corresponding GCD around the nucleus itself) the cholinergic innervation was a phenomenon of the hearing situation and was not restricted to pre-hearing developmental stages.

\section{3 | Both nicotinic and M3 muscarinic receptors are present in the cochlear nucleus}

Up to this point, we mainly focused on presynaptic cholinergic structures. To complement this, we next turned to investigating the presence and localization of cholinergic receptors in the $\mathrm{CN}$ after hearing onset (we used tissue from animals $>$ P25). For this we used $\alpha$-bungarotoxin (BTX) conjugated with alexa555, which specifically binds nicotinic acetylcholine receptors. As a proxy for expression of muscarinic receptors we chose the M3 muscarinic receptor, since it was shown to be expressed in the $\mathrm{CN}$ and is well known to influence the M-current, which we hypothesized to underlie the slow depolarizing responses to carbachol we recorded in spherical bushy cells (Figure 4e).

In parasagittal sections of the CN (Figure 7a-c), Alexa555-BTX reactivity was detected in all three subdivisions, but was stronger in AVCN and rostral PVCN, compared to DCN and caudal PVCN. In contrast, no labeling was visible in the AN providing evidence of the specificity of the toxin staining. Higher magnification of PVCN showed that the labeling was mostly found in the neuropil around large calretininpositive cells (Figure 7b). In contrast to this, Alexa555-BTX reactivity was almost absent in DCN (Figure 7c). In frontal sections of AVCN (Figure 7d-f), Alexa555-BTX signals appeared not uniformly distributed. Here, a stronger labeling appeared in the most lateral and ventral parts of the nucleus, in line with the highest density of cholinergic innervation (see above). Higher magnifications of AVCN revealed the presence of punctate Alexa555-BTX signals surrounding cells which received large calretinin-positive endbulbs of Held (Figure 7e,f), which we interpreted as a dendritic localization of post-synaptic nicotinic receptors on 
SBCs. Interestingly, some Alexa555-BTX-positive reactivity seemed to be located on calretinin-positive endbulbs (yellow dots indicated by arrowheads Figure 7e,f). This may imply that nicotinic receptors play a role in synaptic transmission at endbulbs of Held.

Next, double immunostaining for calretinin (Figure 8a) and for the M3 muscarinic receptor (Figure 8b) was performed. At low magnification, the immunoreactivity for M3 appeared faint and was mostly visible in AVCN and in the rostral GCD just above AVCN (Figure 8b). M3 staining was also weak in DCN even at higher magnification (Figure 8c), as was expected from prior studies (Chen, Waller, \& Godfrey, 1995). M3 immmunoreactive punctae were more perceptible but still sparse throughout PVCN (Figure 8d). In AVCN however, both calretinin-positive (closed arrows in Figure 8e) and -negative cells (open arrows in Figure 8e) showed M3 immunoreactivity. In contrast to the nicotinic receptor staining with Alexa-conjugated BTX, the muscarinic M3 immunosignal was predominantly observed around the cell bodies of neurons and less so in the neuropil, indicating a stronger somatic and weaker dendritic localization of the M3 muscarinic receptors in $\mathrm{CN}$ neurons. Finally, M3 staining in calretinin-negative cells appeared to be stronger overall and with more somatic localization compared to calretinin-positive cells. These last observations were, however, only qualitative. It should be noted, that $\mathrm{CN}$ principal neurons like the SBC can be both calretinin-positive and negative (see Bazwinsky et al., 2008). However, very little is known about the significance of functional subpopulations of SBC that result from this. Our histological findings may suggest further functional diversity of SBC based on expression of muscarinic acetylcholine receptors.

To summarize the investigation of postsynaptic cholinergic structures in the $\mathrm{CN}$ we conclude that both nicotinic and muscarinic receptors were present in the $\mathrm{CN}$. Nicotinic reactivity was present in every subdivision of the $\mathrm{CN}$, but the highest density was noticed in AVCN and rostral PVCN. Our data suggest a more dendritic localization of nicotinic receptors of neurons in PVCN and AVCN, especially around the SBCs. Moreover, first indications also point to a presynaptic occurrence of nicotinic receptors at the endbulb of Held, as shown in Figures 7e,f. Immunolabeling of the M3 muscarinic receptor was present in PVCN and AVCN but we cannot exclude its presence in DCN. The M3 receptor was most often detected in juxtaposition to the soma of calretininpositive and -negative principal neurons (Figure 8f), suggesting a somatic targeting of muscarinic receptors in $\mathrm{CN}$ neurons.

With the present study we showed that the whole $\mathrm{CN}$ is innervated by the cholinergic projections. Cholinergic innervation of the VCN seemed to enter the nucleus on the medial border and proceed in a caudo-rostral direction. Using the AVCN as an example, we have shown that cholinergic projections were not mature at $\mathrm{P} 5$ but progressively invaded the VCN especially around and after hearing onset in a medial to lateroventral manner, in parallel to the development of AN fibers terminating on principal neurons. Both ionotropic and metabotropic receptors were present in $\mathrm{CN}$. The nicotinic receptors were present in each subdivision with a preferred localization in the neuropil, likely in the dendritic membrane. The M3 muscarinic receptor was mostly detected in PVCN and AVCN. Our staining revealed a preferential location on the somatic membrane of neurons in the AVCN including SBCs.
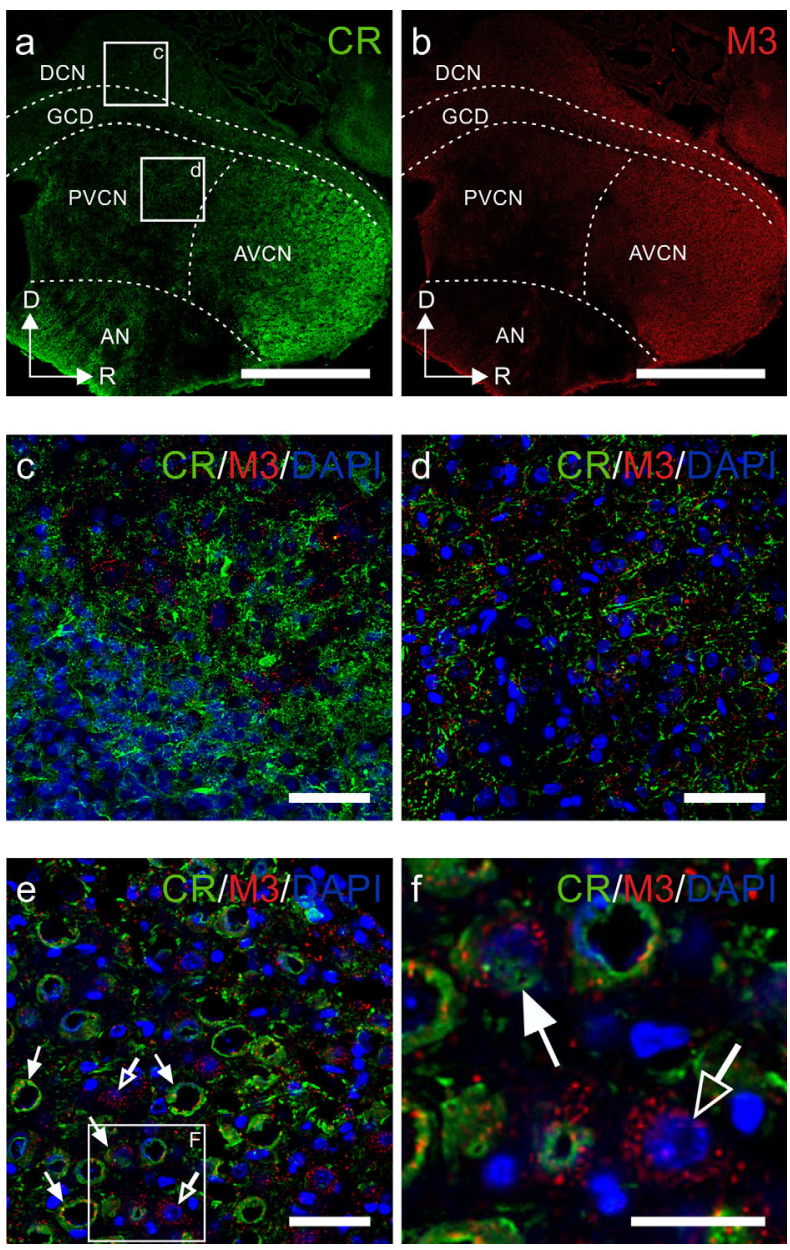

FIGURE 8 M3 muscarinic receptors in the cochlear nucleus of gerbils. Antibodies against calretinin (a) and against M3 muscarinic receptors (b) were used in parasagittal sections of P16-31 gerbil brains, scalebar $=500 \mu \mathrm{m}$. A stronger labeling for M3 was noticed in AVCN. M3-positive staining was only weakly observed in DCN and PVCN but indeed present, as seen in higher magnifications (c) and (d) respectively, scalebar $=50 \mu \mathrm{m}$. (e) In AVCN, there were both calretinin-negative (open arrow) and calretinin-positive cells/ AN terminals (closed arrow), scalebar $=50 \mu \mathrm{m}$. Higher magnification of region indicated by white square showed that both distinguished cell types possessed M3 punctate signal around and on the cell body, scalebar $=25 \mu \mathrm{m}$. AN = auditory nerve,

AVCN = anteroventral part of cochlear nucleus; $\mathrm{CR}=$ calretinin; $\mathrm{DCN}=$ dorsal part of cochlear nucleus; $\mathrm{GCD}=$ granule cell domain; M3 = M3 muscarinic receptor; PVCN = posteroventral part of cochlear nucleus. Section orientation: $\mathrm{D}=$ dorsal; $\mathrm{R}=$ rostral [Color figure can be viewed at wileyonlinelibrary.com]

\section{DISCUSSION}

\subsection{Cholinergic innervation of bushy cell dendrites in the AVCN}

ChAT and VAChT staining showed that cholinergic fibers innervate all subdivisions of the $\mathrm{CN}$. Long segments of cholinergic fibers were revealed in parasagittal sections of AVCN (Figure 4a). However, in frontal sections of AVCN, no such long fibers were detected. This suggests 
that cholinergic fibers preferentially run in a rostro-caudal direction in the AVCN, which was unknown before (cf. Goyer et al., 2016). This however is not unexpected, given the tonotopic organization of the AVCN (reviewed in Ryugo \& Parks, 2003). Thus, we propose that cholinergic axons will roughly run along an iso-frequency layer in the AVCN. Olivocochlear axons, one major source of cholinergic axons in the VCN, provide stimulus-dependent feedback to the periphery and the VCN (Kawase \& Liberman, 1993; Mulders, Seluakumaran, \& Robertson, 2008). The orientation of the cholinergic fibers would therefore facilitate a frequency-matched connection.

Furthermore, the VAChT-positive fibers (Figure 4a) were found in the neuropil between SBCs, where dendrites are found (Gómez-Nieto \& Rubio, 2009). The cholinergic axons formed en-passant swellings, which are similar to those observed on axons from neurons originating in the medial part of SOC (Brown \& Vetter, 2009). The cholinergic fibers thus seem to form mostly axo-dendritic rather than axo-somatic connections. One wonders whether these swellings form synapses in a classical sense. Overall, the density of swellings in relation to the dendrite of our reconstructed SBC seems very sparse. Furthermore, our receptor labeling does suggest small and distributed receptor sites that do not match the sparse but intense presynaptic signals of the VAChT staining. We therefore deem a volume transmission mode more likely (cf. Sarter, Parikh, \& Howe, 2009), which would thus provide the highest concentration of $\mathrm{ACh}$ in the dendritic field of a given SBC, where the nicotinic receptors are found. Nevertheless, close appositions of cholinergic fibers on the soma of SBCs were sparsely observed (open arrowheads in Figure 4a,d), leading to the assumption that for bushy cells with this innervation pattern, a lower and potentially weaker cholinergic influence on the soma, where the muscarinic receptors are situated, would occur. However, this would strongly depend on the sensitivity of the different receptors involved and the overall cholinergic modulatory effect could vary depending on the relative amount of modulatory input each cell compartment receives (cf. Ko, Rasband, Meseguer, Kramer, \& Golding, 2016). Furthermore, SBC seem to form functional groups (Gómez-Nieto \& Rubio, 2009). Our anatomical data would suggest that a closely connected group of SBC could be under common cholinergic influence.

\subsection{Cholinergic receptors in the $\mathrm{CN}$}

The presence of nicotinic receptors was investigated by using $\alpha-B T X, a$ toxin which binds all nicotinic receptors but shows a higher affinity for receptors containing the $\alpha$-subunit. The strongest positive signal was observed in AVCN as well as in rostral PVCN. These results are in agreement with previous electrophysiological data demonstrating the expression of homopentameric $\alpha 7 \mathrm{nAChR}$ on SBCs in gerbil AVCN (Goyer et al., 2016) and the expression of $\alpha 7$ and $\alpha 4 \beta 2$ on T-stellate cells in mouse VCN (Fujino \& Oertel, 2001). Moreover, the BTXpositive punctae were localized mostly in the neuropil of SBCs in AVCN and around cells receiving modified endbulbs in PVCN. This concurs with the localization of cholinergic terminals discussed above and confirms the hypothesis of the dendritic localization of nAChRs in VCN. In contrast to this, BTX staining was much weaker in DCN coinciding with the literature that points to predominantly muscarinic effects in rat (Chen, Waller, \& Godfrey, 1994; Köszeghy et al., 2012; Pál et al., 2009; Yao \& Godfrey, 1995) and in mouse (He et al., 2014; Irie et al., 2006; Zhao \& Tzounopoulos, 2011). In spite of some evidence of muscarinic receptors in $\mathrm{DCN}$, including for the $\mathrm{M} 3$ receptor, our two antibodies against M3 failed to show convincing labeling in any layer of DCN. In addition, M3-positive staining was very faint overall. The weak labeling could be explained by a low density of M3 receptors in gerbil $\mathrm{CN}$. This result is in contradiction with the strong immunopositivity for M3 observed with the same antibody (from MBL international) by Köszeghy et al. (2012) in rat VCN. Nevertheless, some M3-signals were visible at higher magnification of VCN. In AVCN, both calretinin-positive (SBCs) and -negative cells (SBC and/or stellate cells) showed M3 signals with higher density close to the soma (Figure 8f). Contrary to the nAChRs, m3AChRs seem to be most abundant on the soma of AVCN cells, which is in agreement with previous immunohistochemical result in rat (Yao \& Godfrey, 1995). Our results show that nicotinic and muscarinic receptors were differentially distributed: nicotinic receptors were preferentially expressed in the neuropil, whereas muscarinic receptors were more likely to be found on the soma of SBCs. Our immunohistological data provide evidence that somatic m3AChRs could be responsible for the long-lasting depolarization of the resting membrane potential caused by acetylcholine observed by Goyer et al. (2016).

\section{3 | Spatiotemporal expansion of cholinergic axons in AVCN}

Little is known about how the cholinergic fibers develop and enter the AVCN during development. In our study, we have demonstrated through VAChT staining that cholinergic projections were present at low density in AVCN at an early stage of life (P5). At older ages, the innervation density increased significantly, suggesting that the regulation of the quantity of cholinergic fibers might be independent of the onset of hearing. We also investigated where cholinergic axons were located in the AVCN in the different developmental stages. According to our results, cholinergic fibers invade the nucleus beginning on the medial side and propagate to the lateral regions along the ventral (low frequency) and dorsal (high frequency) perimeter of the AVCN. Temporarily this leaves the central, middle frequency part of the AVCN less innervated. In later stages (P28), this was not true anymore. At this point, the highest density of cholinergic signals was found in the ventrolateral, low frequency regions of the AVCN. Nevertheless, all parts of the nucleus were clearly innervated in P28 gerbils. Previous studies in mouse and rat showed a similar innervation pattern as our P15 and younger animals: cholinergic fibers were present in the medial border and at the lateral sides but weaker or even absent in the core of the AVCN (Baashar et al., 2015; Brown \& Vetter, 2009). Although we have to take into account that different methods of staining (acetylcholinesterase immunostaining and specific tracer labeling of MOC collaterals) were applied, the differences are striking. Most physiological reports of central effects of cholinergic OC innervation (Mulders, Paolini, Needham, \& Robertson, 2003, 2008, 2009; Goyer et al., 2016) suggest a 
broad distribution of innervated $\mathrm{CN}$ neurons. Our anatomical data from late hearing animals (P28) seem to confirm this.

\subsection{Differential origin of cholinergic innervation between AVCN and GCD}

Our results show that the cholinergic system also innervated the GCD surrounding the AVCN as early as P5 in higher density than the nucleus itself and the number of fibers also progressively increased over time. The increased innervation density in the GCD is interesting, as the GCD receives multimodal inputs (Ryugo, Haenggeli, \& Doucet, 2003) and some SBCs extend their dendrites into the GCD (Gómez-Nieto \& Rubio, 2009). Our results suggest that descending cholinergic modulation in the GCD, similar to that in the VCN or even to a greater extent, also plays a role in this complex integrative region of the $\mathrm{CN}$.

Moreover, we noticed when comparing the development of the VAChT-signal size that GCD and AVCN cholinergic terminals developed differently. Before hearing onset, the average size of VAChT signals, which we equate with cholinergic axon diameters and/or terminal volume, was similar between the two areas. After hearing onset, the size of VAChT signal in GCD became significantly larger, while this was not the case in AVCN. We therefore hypothesize that cholinergic fibers innervating $A V C N$ and GCD might originate from different regions. Previous studies showed that VCN is innervated by collaterals of the OCB for the major part (Baashar et al., 2015; Brown \& Vetter, 2009; Ryan et al., 1990) but the CN contains also cholinergic axons coming from the pontomesencephalic tegmentum (Mellott et al., 2011; Schofield et al., 2011). It is possible that AVCN and GCD are preferentially innervated by one or the other region, but no evidence in this direction has been provided so far. However, the neuron groups from which the OCB collaterals originate are still controversial. The presence of axons from the thick myelinated medial olivocochlear (MOC) neurons is not questioned but some studies brought to light that also thin unmyelinated lateral olivocochlear (LOC) shell located neurons innervate the VCN (Horváth et al., 2000; Ryan et al., 1990) and more particularly the core of the VCN. On the other hand, MOC neurons were shown to innervate mainly the medial and the superficial layers of the lateral edges of VCN (Baashar et al., 2015; Ryan et al., 1990). The difference in VAChT-signal size we noticed between AVCN and its surrounding GCD could thus be explained by a preferential innervation of GCD by MOC terminals which showed a bigger size and the central AVCN being targeted by LOC neurons. The latter fact might also underlie the peculiar innervation pattern (medial to lateral, peripheral to central) during development which we observed. Possibly, LOC axon-collaterals arrive at a later post-hearing stage in the AVCN. Additionally, a study that performed acetylcholinesterase staining in mouse VCN, which is supposed to stain both MOC and LOC neurons, did not show labeling or very faint in the central VCN (Ryan et al., 1990). It could be that VAChT antibody is better to stain all kinds of cholinergic fibers and terminals and/or that the innervation of LOC neurons to AVCN is greater in gerbil than in mouse.

\section{5 | Functional role of cholinergic modulation}

Several studies showed that the cholinergic system modulates the processing of auditory information in the auditory brainstem, including in the CN (Mulders et al., 2002, 2003, 2009; see Künzel \& Wagner, 2017 for a recent review). Notably neurons in AVCN become more excitable under cholinergic influence (Fujino \& Oertel, 2001; Goyer et al., 2016). In combination with the effect of the OC reflex in the inner ear, which is to unmask a specific tone in noise (Kawase $\&$ Liberman, 1993; Kawase, Delgutte, \& Liberman, 1993; reviewed in: Guinan, 2006), this contributes to increased information transfer through the VCN (Mulders et al., 2008) without losing the temporal precision (Goyer et al., 2016). In the present study, we provided additional anatomical evidence that cholinergic axons are a relevant input to the $\mathrm{CN}$ after the onset of hearing and eventually innervate all tonotopic positions. Indeed, cholinergic innervation substantially develops only after hearing onset. Based on our anatomical data, the cholinergic terminals and receptors in the hearing $\mathrm{AVCN}$ influence information processing through dendritic targets. Thus they influence clusters of principal neurons (cf. Gómez-Nieto \& Rubio, 2009) and can act both pre- and postsynaptically on the information transmission from the $A N$ to central neurons in the $\mathrm{CN}$ and further on into higher centers of hearing.

\section{ACKNOWLEDGMENTS}

We thank Richard Sinzig for his help with immunohistochemical stainings and Michael T. Roberts for comments on the revision of the manuscript.

\section{ORCID}

David Goyer (D) http://orcid.org/0000-0001-7547-8285

Thomas Kuenzel (iD) http://orcid.org/0000-0003-0993-8524

\section{REFERENCES}

Adams, J. C. (1979). Ascending projections to the inferior colliculus. The Journal of Comparative Neurology, 183, 514-538.

Arvidsson, U., Riedl, M., Elde, R., \& Meister, B. (1997). Vesicular acetylcholine transporter (VAChT) protein: A novel and unique marker for cholinergic neurons in the central and peripheral nervous systems. The Journal of Comparative Neurology, 378, 454-467.

Baashar, A., Robertson, D., \& Mulders, W. H. A. M. (2015). A novel method for selectively labelling olivocochlear collaterals in the rat. Hearing Research, 325, 35-41.

Bazwinsky, I., Härtig, W., \& Rübsamen, R. (2008). Characterization of cochlear nucleus principal cells of Meriones unguiculatus and Monodelphis domestica by use of calcium-binding protein immunolabeling. Journal of Chemical Neuroanatomy, 35, 158-174.

Behrens, E. G., Schofield, B. R., \& Thompson, A. M. (2002). Aminergic projections to cochlear nucleus via descending auditory pathways. Brain Research, 955, 34-44.

Brown, M. C., \& Vetter, D. E. (2009). Olivocochlear neuron central anatomy is normal in alpha9 knockout mice. Journal of the Association for Research in Otolaryngology, 10, 64-75.

Campagnola, L., \& Manis, P. B. (2014). A map of functional synaptic connectivity in the mouse anteroventral cochlear nucleus. The Journal of Neuroscience, 34, 2214-2230. 
Cant, N. B., \& Casseday, J. H. (1986). Projections from the anteroventral cochlear nucleus to the lateral and medial superior olivary nuclei. The Journal of Comparative Neurology, 247, 457-476.

Cao, X.-J., \& Oertel, D. (2010). Auditory nerve fibers excite targets through synapses that vary in convergence, strength, and short-term plasticity. Journal of Neurophysiology, 104, 2308-2320.

Caspary, D., Havey, D., \& Faingold, C. (1983). Effects of acetylcholine on cochlear nucleus neurons. Experimental Neurology, 498, 491-498.

Chen, K., Waller, H. J., \& Godfrey, D. A. (1994). Cholinergic modulation of spontaneous activity in rat dorsal cochlear nucleus. Hearing Research, 77, 168-176.

Chen, K., Waller, H. J., \& Godfrey, D. A. (1995). Muscarinic receptor subtypes in rat dorsal cochlear nucleus. Hearing Research, 89, 137-145.

Comis, S. D., \& Davies, E. W. (1969). Acetylcholine as a transmitter in the cat auditory system. Journal of Neurochemistry, 16, 423-429.

Felmy, F., \& Künzel, T. (2014). Giant synapses in the central auditory system. e-Neuroforum, 5, 53-59.

Fujino, K., \& Oertel, D. (2001). Cholinergic modulation of stellate cells in the mammalian ventral cochlear nucleus. The Journal of Neuroscience, 21, 7372-7383.

Grothe, B., Pecka, M., \& McAlpine, D. (2010). Mechanisms of sound localization in mammals. Physiological Reviews, 90, 983-1012.

Grothe, B., \& Pecka, M. (2014). The natural history of sound localization in mammals - a story of neuronal inhibition. Frontiers in Neural Circuits, 8, 1-19.

Gómez-Nieto, R., \& Rubio, M. E. (2009). A bushy cell network in the rat ventral cochlear nucleus. The Journal of Comparative Neurology, 516, 241-263.

Goyer, D., Fensky, L., Hilverling, A. M., Kurth, S., \& Kuenzel, T. (2015). Expression of the postsynaptic scaffold PSD-95 and development of synaptic physiology during giant terminal formation in the auditory brainstem of the chicken. The European Journal of Neuroscience, 41, 1416-1429.

Goyer, D., Kurth, S., Gillet, C., Keine, C., Rübsamen, R., \& Kuenzel, T. (2016). Slow cholinergic modulation of spike probability in ultra-fast time-coding sensory neurons. eNeuro, 3, ENEURO.0186-16.2016.

Guinan, J. J. (2006). Olivocochlear efferents: Anatomy, physiology, function, and the measurement of efferent effects in humans. Ear and Hearing, 27, 589-607.

Happe, H. K., \& Morley, B. J. (1998). Nicotinic acetylcholine receptors in rat cochlear nucleus: [125I]-alpha-bungarotoxin receptor autoradiography and in situ hybridization of alpha 7 nAChR subunit mRNA. The Journal of Comparative Neurology, 397, 163-180.

Harrington, A. M., Peck, C. J., Liu, L., Burcher, E., Hutson, J. M., \& Southwell, B. R. (2010). Localization of muscarinic receptors M1R, M2R and M3R in the human colon. Neurogastroenterology and Motility: The Official Journal of the European Gastrointestinal Motility Society, 22, 999-1008.

He, S., Wang, Y.-X., Petralia, R. S., \& Brenowitz, S. D. (2014). Cholinergic modulation of large-conductance calcium-activated potassium channels regulates synaptic strength and spine calcium in cartwheel cells of the dorsal cochlear nucleus. The Journal of Neuroscience, 34 , 5261-5272.

Held, H. (1893). Die centrale Gehörleitung. Arch für Anatomie und Physiologie, A3 + 4, 201-248.

Horváth, M., Kraus, K. S., \& Illing, R. B. (2000). Olivocochlear neurons sending axon collaterals into the ventral cochlear nucleus of the rat. Journal of Comparative Neurology, 422, 95-105.

Irie, T., Fukui, I., \& Ohmori, H. (2006). Activation of GIRK channels by muscarinic receptors and group II metabotropic glutamate receptors suppresses Golgi cell activity in the cochlear nucleus of mice. Journal of Neurophysiology, 96, 2633-2644.

Kawase, T., \& Liberman, M. C. (1993). Antimasking effects of the olivocochlear reflex. I. Enhancement of compound action potentials to masked tones. Journal of Neurophysiology, 70, 2519-2532.

Kawase, T., Delgutte, B., \& Liberman, M. C. (1993). Antimasking effects of the olivocochlear reflex. II. Enhancement of auditory-nerve response to masked tones. Journal of Neurophysiology, 70, 25332549.

Keine, C., \& Rübsamen, R. (2015). Inhibition Shapes Acoustic Responsiveness in Spherical Bushy Cells. Journal of Neuroscience, 35, 85798592.

Keine, C., Rübsamen, R., \& Englitz, B. (2016). Inhibition in the auditory brainstem enhances signal representation and regulates gain in complex acoustic environments. Elife, 5, 1-33.

Kishan, A. U., Lee, C. C., \& Winer, J. A. (2011). Patterns of olivocochlear axonal branches. Open Journal of Neuroscience, 1, 145-149.

Ko, K. W., Rasband, M. N., Meseguer, V., Kramer, R. H., \& Golding, N. L. (2016). Serotonin modulates spike probability in the axon initial segment through HCN channels. Nature Neuroscience, 19, 826-834.

Kőszeghy, Á., Vincze, J., Rusznák, Z., Fu, Y., Paxinos, G., Csernoch, L., \& Szücs, G. (2012). Activation of muscarinic receptors increases the activity of the granule neurones of the rat dorsal cochlear nucleus-a calcium imaging study. Pflugers Archiv, 463, 829-844.

Kuenzel, T., Borst, J. G. G., \& van der Heijden, M. (2011). Factors controlling the input-output relationship of spherical bushy cells in the gerbil cochlear nucleus. Journal of Neuroscience, 31, 4260-4273.

Kuenzel, T., Nerlich, J., Wagner, H., Rübsamen, R., \& Milenkovic, I. (2015). Inhibitory properties underlying non-monotonic input-output relationship in low-frequency spherical bushy neurons of the gerbil. Frontiers in Neural Circuits, 9, 1-14.

Künzel, T., \& Wagner, H. (2017). Cholinergic top-down influences on the auditory brainstem. e-Neuroforum, 23, 35-44.

Kopp-Scheinpflug, C., Dehmel, S., Dörrscheidt, G. J., \& Rübsamen, R. (2002). Interaction of excitation and inhibition in anteroventral cochlear nucleus neurons that receive large endbulb synaptic endings. The Journal of Neuroscience, 22, 11004-11018.

Limb, C. J., \& Ryugo, D. K. (2000). Development of primary axosomatic endings in the anteroventral cochlear nucleus of mice. Journal of the Association for Research in Otolaryngology, 1, 103-119.

Manzoor, N. F., Chen, G., \& Kaltenbach, J. A. (2013). Suppression of noise-induced hyperactivity in the dorsal cochlear nucleus following application of the cholinergic agonist carbachol. Brain Research, 1523, 28-36.

Mellott, J. G., Motts, S. D., \& Schofield, B. R. (2011). Multiple origins of cholinergic innervation of the cochlear nucleus. Neuroscience, 180, 138-147.

Mulders, W. H. A. M., Winter, I. M., \& Robertson, D. (2002). Dual action of olivocochlear collaterals in the guinea pig cochlear nucleus. Hearing Research, 174, 264-280.

Mulders, W. H. A. M., Paolini, A. G., Needham, K., \& Robertson, D. (2003). Olivocochlear collaterals evoke excitatory effects in onset neurones of the rat cochlear nucleus. Hearing Research, 176, 113121.

Mulders, W. H. A. M., Seluakumaran, K., \& Robertson, D. (2008). Effects of centrifugal pathways on responses of cochlear nucleus neurons to signals in noise. European Journal of Neuroscience, 27, 702-714.

Mulders, W. H. A. M., Paolini, A. G., Needham, K., \& Robertson, D. (2009). Synaptic responses in cochlear nucleus neurons evoked by activation of the olivocochlear system. Hearing Research, 256, 85-92. 
Nerlich, J., Kuenzel, T., Keine, C., Korenic, A., Rübsamen, R., \& Milenkovic, I. (2014). Dynamic fidelity control to the central auditory system: Synergistic glycine/GABAergic inhibition in the cochlear nucleus. The Journal of Neuroscience, 34, 11604-11620.

Nordeen, K. W., Killackey, H. P., \& Kitzes, L. M. (1983). Ascending auditory projections to the inferior colliculus in the adult gerbil, Meriones unguiculatus. The Journal of Comparative Neurology, 214, 131-143.

Oertel, D. (1983). Synaptic responses and electrical properties of cells in brain slices of the mouse anteroventral cochlear nucleus. The Journal of Neuroscience, 3, 2043-2053.

Pál, B., Koszeghy, A., Pap, P., Bakondi, G., Pocsai, K., Szucs, G., \& Rusznák, Z. (2009). Targets, receptors and effects of muscarinic neuromodulation on giant neurones of the rat dorsal cochlear nucleus. The European Journal of Neuroscience, 30, 769-782.

Ryan, A. F., Keithley, E. M., Wang, Z. X., \& Schwartz, I. R. (1990). Collaterals from lateral and medial olivocochlear efferent neurons innervate different regions of the cochlear nucleus and adjacent brainstem. The Journal of Comparative Neurology, 300, 572-582.

Ryugo, D. K., Haenggeli, C.-A., \& Doucet, J. R. (2003). Multimodal inputs to the granule cell domain of the cochlear nucleus. Experimental Brain Research, 153, 477-485.

Ryugo, D., \& Parks, T. N. (2003). Primary innervation of the avian and mammalian cochlear nucleus. Brain Research Bulletin, 60, 435-456.

Sarter, M., Parikh, V., \& Howe, W. M. (2009). Opinion: Phasic acetylcholine release and the volume transmission hypothesis: Time to move on. Nature Reviews Neuroscience, 10, 383-390.

Schofield, B. R., Motts, S. D., \& Mellott, J. G. (2011). Cholinergic cells of the pontomesencephalic tegmentum: Connections with auditory structures from cochlear nucleus to cortex. Hearing Research, 279, 85-95.
Sherriff, F. E., \& Henderson, Z. (1994). Cholinergic neurons in the ventral trapezoid nucleus project to the cochlear nuclei in the rat. Neuroscience, 58, 627-633.

Smith, D. I., \& Kraus, N. (1987). Postnatal development of the auditory brainstem response (ABR) in the unanesthetized gerbil. Hearing Research, 27, 157-164.

Stefanescu, R. A., \& Shore, S. E. (2016). Muscarinic acetylcholine receptors control baseline activity and Hebbian stimulus-timing dependent plasticity in fusiform cells of the dorsal cochlear nucleus. Journal of Neurophysiology, 117, 1229-1238.

Wickesberg, R. E., \& Oertel, D. (1988). Tonotopic projection from the dorsal to the anteroventral cochlear nucleus of mice. The Journal of Comparative Neurology, 268, 389-399.

Woolf, N. K., \& Ryan, A. F. (1985). Ontogeny of neural discharge patterns in the ventral cochlear nucleus of the mongolian gerbil. Brain Research, 349, 131-147.

Yao, W., \& Godfrey, D. A. (1995). Immunohistochemistry of muscarinic acetylcholine receptors in rat cochlear nucleus. Hearing Research, 89, 76-85.

Zhao, Y., \& Tzounopoulos, T. (2011). Physiological activation of cholinergic inputs controls associative synaptic plasticity via modulation of endocannabinoid signaling. The Journal of Neuroscience, 31, 3158-3168.

How to cite this article: Gillet C, Goyer D, Kurth S, Griebel H, Kuenzel T. Cholinergic innervation of principal neurons in the cochlear nucleus of the Mongolian gerbil. J Comp Neurol. 2018;526:1647-1661. https://doi.org/10.1002/cne.24433 